Comparative cortical bone thickness between the long bones of humans and five common non-human mammal taxa.

Sarah L. Croker ${ }^{\mathrm{a} *}$, Warren Reed ${ }^{\mathrm{b}}$, Denise Donlon ${ }^{\mathrm{a}}$.

${ }^{\text {a }}$ Discipline of Anatomy and Histology, Building F13, School of Medical Sciences, Bosch Institute, The University of Sydney, NSW 2006 Australia.

${ }^{\mathrm{b}}$ Medical Image Optimisation and Perception Group (MIOPeG), Medical Imaging \& Radiation Sciences, Faculty Research Group, The Faculty of Health Sciences, The University of Sydney, Cumberland Campus, 75 East Street, Lidcombe, NSW 2141, Australia.

* Corresponding author:

Sarah L. Croker

Discipline of Anatomy and Histology

Building F13,

The University of Sydney

NSW 2006 Australia

Phone +61 293516545

Emailsarah.croker@sydney.edu.au 


\title{
Comparative cortical bone thickness between the long bones of humans and five common non- human mammal taxa.
}

\begin{abstract}
The task of identifying fragments of long bone shafts as human or non-human is difficult but necessary, for both forensic and archaeological cases, and a fast simple method is particularly useful. Previous literature suggests there may be differences in the thickness of the cortical bone between these two groups, but this has not been tested thoroughly. The aim of this study was not only to test this suggestion, but also to provide data that could be of practical assistance for future comparisons. The major limb bones (humerus, radius, femur and tibia) of 50 Caucasoid adult skeletons of known age and sex were radiographed, along with corresponding skeletal elements from sheep, pigs, cattle, large dogs and kangaroos. Measurements were taken from the radiographs at five points along the bone shaft, of shaft diameter, cortical bone thickness, and a cortical thickness index (sum of cortices divided by shaft diameter) in both anteroposterior and mediolateral orientations. Each variable for actual cortical bone thickness as well as cortical thickness indices were compared between the human group (split by sex) and each of the non-human groups in turn, using Student's t-tests. Results showed that while significant differences did exist between the human groups and many of the non-human groups, these were not all in the same direction. That is, some variables in the human groups were significantly greater than, and others were significantly less than, the corresponding variable in the non-human groups, depending on the particular non-human group, sex of the human group, or variable under comparison. This was the case for measurements of both actual cortical bone thickness and cortical thickness index. Therefore, for bone shaft fragments for which the skeletal element is unknown, the overlap in cortical bone thickness between different areas of different bones is too great to allow identification using this method alone. However, by providing extensive cortical bone thickness data for a range of bones, this study may be able to assist in the identification of some bone fragments by providing another piece of evidence that, used in conjunction with other clues, can provide a likely determination of the origin of a bone fragment.
\end{abstract}

\section{Keywords}

Non-human bone; cortical bone thickness; skeletal identification; comparative anatomy; radiogrammetry; forensic anthropology population data. 


\section{Introduction}

When skeletal remains are discovered, the identification of bone as human or non-human in origin is one of the earliest and most crucial steps. If the bones are intact, or at least display diagnostic features, identification can be made by observing the external morphology [1]. Yet if the remains are fragmented, such identifying features may not be evident. This is particularly problematic with the shafts of long bones, which not only lack diagnostic features but are reasonably robust, ensuring relatively long-term survival and therefore a potentially higher incidence of discovery. A number of technical methods have been developed that may be capable of accurately identifying bone as human or non-human, such as histological analysis [2-7], immunological analysis [8], x-ray diffraction analysis [9] and DNA analysis [2, 10-12]. However, such methods require specialist laboratory facilities, can take time to perform (especially considering the potentially lengthy backlogs in forensic laboratories) and require destruction of part of the sample. Therefore such methods are not ideal for many crime scenes or archaeological sites, where a fast, simple, inexpensive, non-destructive method would be more useful in order to process the site correctly.

Suggestions in the literature indicate a potential difference in the thickness of the cortical bone of the long bone shafts between human and non-human mammals that may be useful in identification [1316]. Considering that an assessment of the cortical bone thickness would be possible in the majority of long bone shaft fragments, without the use of complicated laboratory techniques or further destruction of the fragment, such a method would have great practical application. Brothwell [13] mentioned simply that there is a difference in bone thickness between different mammals; although the context inferred humans, no further detail was provided. Ubelaker [14] stated that the bone cortex of most non-human animals similar in size to humans is usually thicker. Specific details concerning the particular skeletal elements and non-human taxa were not given. Wolf [15] agreed that non-human cortical bone is relatively thicker than that of the human. He used the example of a femur or humerus, stating that the thickness of the cortical bone in the human is one-quarter of the total bone diameter (presumably just one side of the bone cortex). This was followed by a diagram (not to scale), the text of which stated that for large mammals, such as deer, cattle, horses and sheep, the thickness of the cortical bone is one-third of the total bone diameter.

Other researchers have found differences in the opposite direction. Croker et al. [16] found that, at the midshaft of the femur, the cortex of human bones was significantly thicker than either sheep or kangaroos. This was calculated by determining the mean proportion of the shaft diameter that was occupied by the cortical bone in a cross-section. For the human sample, this was $51.5 \%$, whereas for the kangaroo it was $34.6 \%$ and for the sheep just $25.2 \%$. Foote [17] also compared the femora of humans and a great number of animal species, by formulating a "medullary index", essentially a ratio representing the size of the medullary cavity compared with the thickness of the cortical bone. The 
index, calculated as the ratio of the mean diameter of the medullary cavity (squared and multiplied by 100) to the difference between the mean bone diameter squared and the mean medullary cavity squared, is high in animals where the medullary cavity is large compared with the cortical bone. The mean index for human femora was $38.6 \%$ and for the 117 non-human species the overall mean was $63.3 \%$. Therefore Foote's [17] study also found human femora to have relatively thicker cortical bone than non-human femora. Urbanová and Novotný [18] measured cortical bone thickness in the femur as part of their histomorphometric comparative study, and stated that, of the common non-human mammals studied, only pigs were similar in cortical bone thickness to humans. Analysis of this feature alone was not presented, but they found that by incorporating cortical bone thickness into the discriminant functions for their histological analysis, the diagnostic capability of the functions was improved. On the other hand, Rérolle et al. [19] do not believe there is enough difference in the relative cortical bone thickness of long bones to distinguish human from non-human (pig, dog and sheep) bones. Their article considered the corticomedullary index (the ratio of the diameter of the medullary cavity to the external shaft diameter of the bone), but the samples used for reference values are not well-described.

As suggested in the study by Croker et al. [16], the various points of confusion in the current literature show that there is a need for a thorough comparison of human and non-human cortical bone thickness. Different areas of the bone shaft should be incorporated, as should several different long bones and a wide range of non-human mammals, to explore more clearly the possibilities and limitations of this method. This is the overall purpose of the study presented here. Studies such as those of Croker et al. [16] have only considered the midpoint of the shaft, yet bone thickness can vary along the shaft [19, 20]. Several different skeletal elements are comparable between taxa in terms of overall size and shaft form, so the major long bones of humerus, radius, femur and tibia at least should be included. An effective comparison of bone thickness from a forensic viewpoint should include several non-human taxa that are likely to be confused with humans locally. In this case, sheep, kangaroos, juvenile pigs, large dogs (greyhound type) and cattle were chosen due to the broad similarity in size (or at least diameter) of their long bones when compared with adult humans and the frequency with which they are presented for expert identification, at least in the Sydney region in Australia.

As it is not clear how some of the figures in the literature have been derived, the first aim of this study is to quantify long bone shaft diameters and cortical bone thicknesses for adult humans and several common non-human mammals. Presenting these actual data will provide an important benchmark in allowing meaningful comparisons to be made for both past and future research. The second aim of the study is to determine whether there are significant differences in the cortical bone thickness between the adult humans and non-human mammals in the study. These are compared in terms of both the 
actual cortical bone thickness measurements themselves, and a cortical bone thickness index that takes into account the shaft diameter.

\section{Materials}

The human sample was sourced from the Robert J. Terry Collection, housed at the National Museum of Natural History in Washington, D.C., USA. This collection was used because there are known biological data for these remains, which was important to control for as previous research has shown that factors such as age and sex may affect cortical bone thickness [21-23]. Adult Caucasoid specimens from age 24 years to 86 years were used (see Table 1). The specimens were selected so that approximately two to three years separated the ages of each male and female specimen, ensuring as even as possible a spread of ages across the sample. Within these guidelines, the specimens were chosen at random from their catalogue numbers. Right and left sides were sampled equally, also chosen at random from the catalogue. The humerus, radius, femur and tibia from the same side of each individual were sampled. Apart from traces of osteoarthritis in some of the older individuals, there were no externally obvious pathological conditions in the sample selected, though it was not possible to determine beforehand if any of the individuals were osteoporotic.

The non-human sample (comprised of kangaroos, sheep, pigs, dogs and cattle) originated from a number of sources, explained in more detail below. For the majority of specimens, no specific age and sex data were known, though some indication could be gained for most taxa by observing epiphyseal fusion. Unlike the human sample, for many of the non-human specimens each skeletal element may have been from a different individual, rather than testing all four skeletal elements from the one individual. Many specimens were acquired fresh and had to be defleshed, macerated, degreased, dried and the epiphyses glued on before being used. In this sample, the epiphyses were fully formed with only a very minimal layer of cartilage separating the epiphyseal plate; thus reattaching the epiphyses in this way did not appreciably alter the total length of the bone. Table 1 shows the number of each type of bone used.

Kangaroos of medium-large size were used. Initially, six to seven very large kangaroo bones for each element type were also included for analysis, but a plot of their dimensions showed these very large specimens to form a distinct group from the more medium-sized specimens. The large bones were not included in the analysis in order to create a more homogeneous group for statistical comparison. All bones selected had epiphyses present in order that total bone length could be measured, although in most cases these were attached with adhesive putty or glued in place as they had not fused. Of the bones from known specimens, twelve femora and eight tibiae were Macropus fuliginosus; one femur was Macropus rufus and four femora and three tibiae were from Macropus giganteus; of this total, seven of the bones were from male kangaroos and 21 from female. The species and sex of the 
remaining specimens was not known, though $57 \%$ of the total bones were sourced from a kangaroo meat supplier, and the four species commercially harvested in NSW are Macropus giganteus, Macropus rufus, Macropus fuliginosus and, minimally, Macropus robustus [24]. As a guide to what is meant by "medium-sized" specimens, the ranges in length for the selected skeletal elements were as follows: humerus 100 - $175 \mathrm{~mm}$; radius 143 - $255 \mathrm{~mm}$; femur $172-239 \mathrm{~mm}$; tibia $328-481 \mathrm{~mm}$. Sheep specimens were sourced from institutions, butchers and pet food merchants. These ranged from adult specimens (50\% of bones) to young sheep intended for human consumption (6-12 months). Pig specimens were obtained from butchers, and were therefore juveniles of approximately five months old, this being the age of slaughter [25]. Dog specimens were of greyhound breed (or breeds indistinguishable from greyhounds by their size and long, slender skeletal morphology). Almost all were from adult dogs; six bones were estimated to be from juveniles 8-18 months old. Cattle specimens comprised adults (22\% of bones), as well as juveniles purchased from butchers (and therefore from beef breeds and of a likely slaughter age of 15 to 18 months [26]) and pet food merchants.

\begin{tabular}{lllcccc}
\hline \multirow{2}{*}{ Group } & \multirow{2}{*}{ Sex } & \multirow{2}{*}{ Age range } & \multicolumn{3}{c}{ Number of each skeletal element } \\
& & & Humerus & Radius & Femur & Tibia \\
\hline Human & Male & 27-85 years & 25 & 25 & 25 & 25 \\
& Female & 24-86 years & 25 & 25 & 25 & 25 \\
\multirow{2}{*}{ Kangaroo } & Mostly unknown & Presume adult & 9 & 24 & 30 & 24 \\
Sheep & Unknown & Approx. 6 months-adult & 24 & 27 & 28 & 24 \\
Pig (juvenile) & Unknown & Approx. 5 months & 18 & 22 & 27 & 23 \\
Dog (greyhound) & Unknown & Mostly adult & 19 & 22 & 17 & 18 \\
Cattle & Unknown & Approx. 15 months-adult & 29 & 28 & 24 & 24 \\
\hline
\end{tabular}

Table 1. Summary of specimens used.

For each group and each skeletal element, samples were checked for normal patterns of distribution for every tested variable using Shapiro-Wilks tests, as well as histograms and boxplots for visual confirmation, using the XLSTAT analysis program [27]. A few outliers were identified and removed: a specimen was considered an outlier if three or more of its variables had values more than three standard deviations away from the mean. Following this, most variables within each group and skeletal element were normally distributed, and it is this number of specimens that is shown in Table 1.

\section{Methods}

The total length for all bones was measured on an osteometric board to the nearest millimetre, and was taken from the most proximal point on the proximal articulation of each bone, to the most distal 
point on the distal articulation, with the shaft of the bone parallel to the long axis of the osteometric board. In the case of the tibia, the total length was taken from the most proximal point on the intercondylar eminence to the tip of the medial malleolus. In this way, projecting non-articular features were not considered, making for more even comparison between human and non-human elements.

From the total length, the midpoint of each bone was calculated, and marked on the bone for radiography by taping a tiny piece of metal to the bone. The other measurement sites were located at $30 \%, 40 \%, 60 \%$ and $70 \%$ of the total bone length (midpoint being at the 50\% mark, and the point from which the other measurement positions were determined on the radiograph), here referred to as "length levels" (Figure 1). These upper and lower boundaries were chosen because the distance between them usually represented the part of the bone shaft that appeared morphologically the most comparable and representative of "typical" bone shaft (with a few exceptions).

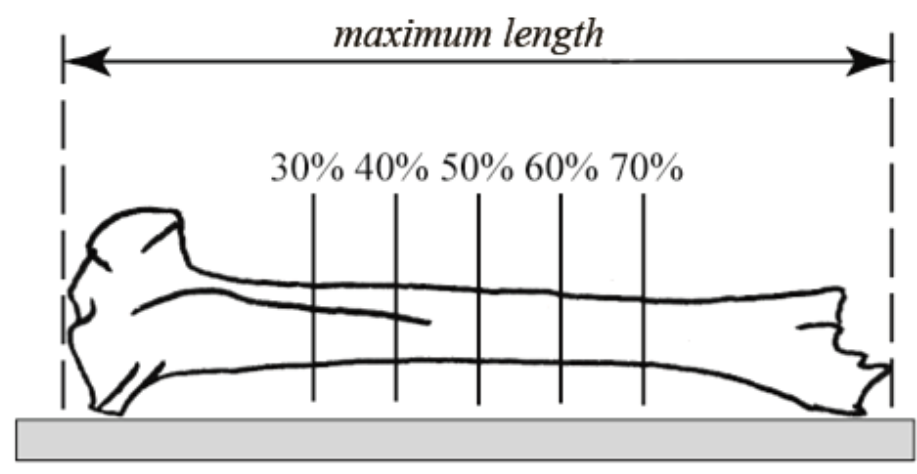

Figure 1. Position of measurement sites (termed "length levels") along shaft of long bone.

All bones were radiographed in both anteroposterior and mediolateral projections. Due to the different sizes of bones under comparison, the potential effects of radiographic magnification had to be countered. The projection of bone from the surface of the film was reduced by radiographing the bone so that its shaft lay as flat as possible on the image receptor (thus some "anteroposterior" projections were taken with the posterior side of the bone uppermost, the femur being one example). It is possible to calculate the magnification [28]. Accordingly, at each length level along the bone shaft, a magnification factor was calculated by dividing the distance between the focus to the film or detector, by the difference between that distance and the distance of the object to the film or detector. The height of the object was taken to be at a level equivalent to the centre of the shaft diameter, as this is the best approximation of where the shaft diameter on the radiograph would be measured. Therefore, at each measurement site, the height of the upper surface of the bone from the film or detector was measured, and half the diameter of the bone at that point was subtracted from this to obtain the point at which the magnification factor was effective. (For the human bones, time constraints meant that the 
height of the bone at only the 30\%,50\% and 70\% length levels were measured for the calculation of the magnification factor, with those in between estimated from these).

The radiography of the human sample was carried out on a Collimax mobile machine (manufactured by Porta Ray Inc.; collimator model P180HS). The film (Kodak Ektascan B/RA film) was of 35 x 43 cm size, used with Kodak X-Omat Lanex Fine/Single Screen cassettes, and processed using an automatic processor (Kodak X-Omat 2000A). The focus to film distance was $100 \mathrm{~cm}$. Exposure times and settings varied for each element due to the different bone densities. In some cases, settings were changed for different bones of the same skeletal type that did not expose well under the usual settings. The settings used for each skeletal element were: humerus - either $80 \mathrm{kV}$ for 0.4 seconds or $60 \mathrm{kV}$ for 0.5 seconds; radius - $60 \mathrm{kV}$ for 0.4 or 0.5 seconds; femur - either $80 \mathrm{kV}$ for 0.5 seconds, or $60 \mathrm{kV}$ for 0.6, 0.7 or 0.8 seconds; tibia - either $80 \mathrm{kV}$ at 0.5 seconds or $60 \mathrm{kV}$ at 0.7 seconds (all at $80 \mathrm{~mA}$ ). Each bone was radiographed singly, placed as directly under the beam as possible in order to reduce distortion.

The non-human bones were radiographed digitally, using a Shimadzu X-ray tube and generator. An AGFA Computer Radiography system was used in conjunction with AGFA ADCC MD 40 CR phosphor plates (plate size either $24 \times 30 \mathrm{~cm}$ or $35 \times 43 \mathrm{~cm}$ ). Images were processed in an AGFA ADC Solo CR reader (AGFA Healthcare, Peissenberg, Germany). Viewing the images after they had been taken was by a secondary class NEC MultiSync LCD 2010X display monitor (NEC Corp, Kanagawa, Japan) with 1280 x 1024 resolution. The focus to detector distance was $100 \mathrm{~cm}$. As with the human sample, each bone was radiographed singly directly beneath the beam. Although bones of quite different density were being radiographed, the digital system compensates for this, so that fine adjustments to the radiographic settings are not required in the same way as with traditional film radiography. The settings for almost all the bones radiographed were $50 \mathrm{kV}$ for 0.08 seconds at $100 \mathrm{~mA}$; some denser cattle bones were radiographed at $54 \mathrm{kV}$. Although these settings are different to those used for the human sample (particularly regarding the time), in each case settings were used that achieved the best possible radiographic result. The non-human images were digitally processed using AGFA Multi-Scale Image Contrast Amplification (MUSICA) processing software. The algorithm used was: adult bone, lower extremities, femur. The femur algorithm was used for all images, irrespective of element, because the algorithm allows the digital system to alter the image depending on what part of the body is being radiographed, presuming a fleshed human body. Such adjustments, which cannot be controlled, were not desired here in the interests of making all radiographs as standardised as possible.

The films of the human sample were scanned using a flat-bed scanner (Sharp JX-610), at 600 dpi resolution, and saved in TIFF format. The scanned files were viewed and measured using OsiriX 
imaging software [29], a freely available program. In the case of the scanned images, calibrations had to be made by radiographing metal rulers of known length, to ensure the distances determined by the program were correct. For the digital images of the non-human sample, the images were imported as DICOM images into the OsiriX program, and no such calibration was required. Although it would have been preferable to use the same system for all bones, this was not logistically possible at the time, and studies (such as that by Lund et al. [30]) have found the results from the two systems to be quite similar.

The OsiriX software offers different colours in which images may be viewed; the colour scheme called "Flow" was used, which interpreted the radio-opaque parts of the images as red, and the radiolucent areas as blue. This assisted in visualising the bone and determining the most appropriate contrast in which to view each image. For consistency, contrast was generally adjusted so that bone appeared as a clear red or red/orange colour, though depending on the original contrast of the radiograph, this was sometimes difficult. Radiographs were also checked in the traditional black and white form, to ensure that the "Flow" colour scheme was not erroneously highlighting a feature that would otherwise not be recorded by an operator using the standard black and white viewing. In many cases, measurements that were difficult to record were made easier by toggling between the "Flow" and black and white options. Often, shaft widths were easiest to observe with the "Flow" option, and thin cortical bone, often at the ends of bones and adjacent to cancellous bone, was easiest to observe in black and white.

Images were enlarged to five times their actual size, at which magnification the OsiriX program calculates lengths to the nearest 0.06 or $0.07 \mathrm{~mm}$ (rounded by the program). At each length level, in each projection, the measurements taken were firstly, diameter of the entire bone shaft; secondly, diameter of the medullary cavity; thirdly, the width of the cortex on either side of the medullary cavity (Figure 2). During the measurement process, the figure for each cortex was added to that of the medullary cavity and if the total did not agree exactly with the figure for the shaft diameter, the measurements were retaken.

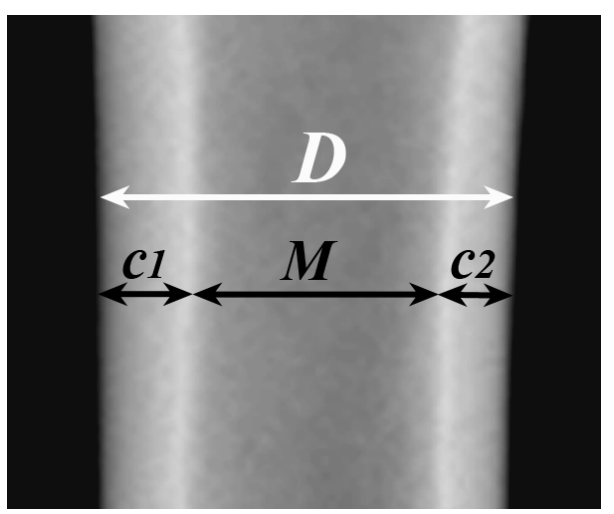

Figure 2. Measurements taken at each length level on each radiograph. $D=$ total shaft diameter; $M=$ medullary cavity diameter; $c l=$ cortex width one side; $c 2=$ cortex width opposite side to $c l$. 
Difficulties were encountered in locating exactly the endosteal borders of the cortex in many bones. Resorption of bone on the endosteal surface could interrupt the border of the cortical bone, creating gaps, spurs and bridges of trabeculae. To deal with this consistently, the guidelines set down by Meema and Meema [31], and restated by Ives and Brickley [32], were generally followed. If a spur of bone projected into the medullary cavity, and did not rejoin the cortex, the measurement was taken at the cortical surface below this spur (Figure 3a). Meema and Meema [31] suggest that if a spur does rejoin the cortex, then the measurement should be taken from the endosteal surface of the spur (Figure $3 b)$. However, these guidelines were based upon measurements on radiographs of the human second metacarpal and the proximal radius, which are small, dense, relatively easily defined areas of cortical bone. The current study included a much greater variety of species, bones and measurement sites with a correspondingly large variety of cortical bone appearances, including many bones that contained cancellous bone adjacent to the cortical bone. To avoid erroneously including a lot of cancellous bone in cortical bone measurements in situations where the bone contained large spaces in the vicinity of the endosteal border, the cortex was determined as starting where there was a dense, relatively uninterrupted section of bone running all the way from the measurement point to the periosteal border (Figure 3c). For bone that was clearly cortical bone, yet was slightly porous with small gaps visible, these small sliver-like gaps were included in the measurement of cortical thickness if they appeared to be incorporated into what was obviously the entire cortex (Figure 3d), as this is what would happen if the cortex was measured directly. If large holes were present in the area of the endosteal border, but not at the precise measurement site, then the measurement was taken irrespective of the large holes in the surrounding context, as there was deemed to be "dense, uninterrupted cortex" from the point of measurement all the way to the periosteal border (Figure 3e). Cancellous bone was usually fairly easy to distinguish, with the help of these criteria. A special case was where a nutrient foramen joined the

a)

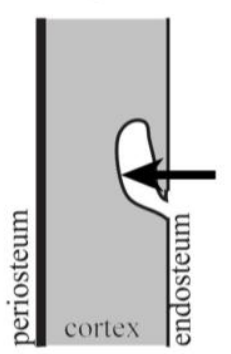

b)

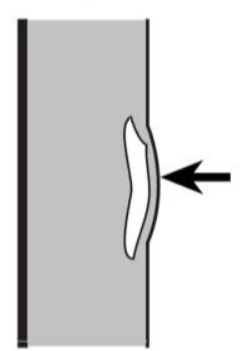

c)

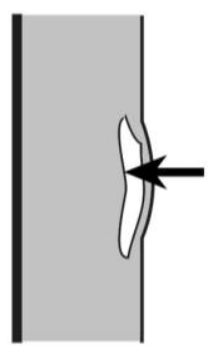

d)

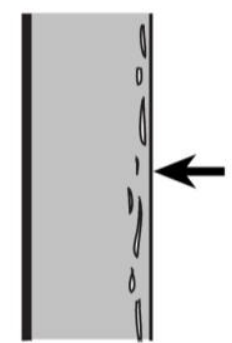

e)

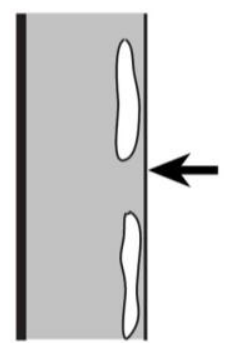

f)

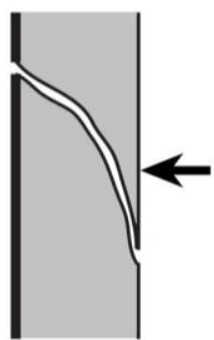

Figure 3. Guidelines for endosteal border definitions. Arrow indicates definition of endosteal border if measurement site fell at that point. a) Spur of bone does not rejoin cortex (after Meema and Meema [31]); b) Meema and Meema's [31] definition of endosteal border for bridge of bone - not used in this study; c) Definition of endosteal border for bridge of bone over large gap as used in this study;

d) Cortex containing small "sliver-shaped" gaps; e) Cortex containing large holes, but not at measurement site; f) Cortex containing nutrient foramen. 
medullary cavity. Because a space due to the transport of a vessel was not deemed to interfere with or reflect upon the width of the cortex at that point, nutrient foramina were not considered "gaps", and the measurement for cortical thickness was taken at the endosteal border of the bone through which the channel ran (Figure 3f).

For certain regions of some bones, the cortex was extremely difficult to distinguish from the medullary cavity, as the endosteal border appeared blurred and no delineation from the medullary cavity was obvious. Adjustments of contrast and toggling between colour modes frequently helped, but in some instances, the cortex simply could not be distinguished and no measurement was recorded in these cases.

\section{Cortical thickness index}

In addition to recording the shaft diameter and cortical bone thickness at each measurement site, an index showing the relationship between these two figures, termed the cortical thickness index, was also calculated, in order that comparisons of relative bone thickness could be made between skeletal elements of different sizes. This cortical thickness index was calculated as the sum of both cortices ( $c 1$ and $c 2$ ) visible in a radiographic projection, divided by the shaft diameter $(D)$ at the same point. Thus:

Cortical thickness index $=(c 1+c 2) / D$

\section{Statistical analysis}

As the objective of this study was the comparison of human with non-human samples (rather than the direct comparison of different non-human groups with each other), Student's t-tests were used to test human groups against each of the non-human groups in turn, for every variable, including cortical thickness index. The human sample was divided into male and female, $t$-tests having revealed that there were statistically significant differences between the sexes for all but nine variables of the entire set of variables tested (no clear patterns were found regarding age in this sample).

\section{Observer error tests}

In order to examine intraobserver error, a subset of 108 radiographs was selected: four of each nonhuman skeletal element (except three for kangaroo humerus and five for kangaroo femur), and seven of each human element. Within each taxon and element category, radiographs were chosen randomly. Each radiograph was remeasured by the original observer by calculating the measurement sites along the shaft and measuring as for the collection of the main dataset (not including magnification calibrations). 
A further test of the reproducibility of the radiographs themselves was made by radiographing another subset of bones, with the same observer then rerecording the data from the new radiographs. Four specimens for each skeletal element and taxon (three for kangaroo humerus and anteroposterior projection of human tibia) were selected randomly as for the other intraobserver error test.

Interobserver accuracy was also tested, with a second observer measuring a subset of 59 radiographs (two from each non-human taxon and skeletal element, except three for kangaroo radius, femur and tibia; and four from each human skeletal element), selected randomly as for the other reproducibility tests. This observer was provided with the same measuring criteria as explained above. Magnification factors were not calculated.

For all observer error tests, the measurement errors were calculated as described by White and Folkens [33]; the first and subsequent measurements are averaged, then the difference between each of the measurements and the mean is summed and divided by the number of measurements. This is expressed as a percentage of the mean value of the measurement.

\section{Results}

\section{Observer error tests}

The mean measurement errors for all tests were lower for measurements of the shaft rather than the cortical bone thickness (Table 2). This is not unexpected as the shaft was easier to define, and its larger figure would be more tolerant of small deviations than the smaller measurement of cortical bone thickness. The lowest percentage errors arose when the same radiograph was measured a second time (Table 2 part a), particularly the shaft, which frequently gave the same measurement both times. The exception was for the mediolateral kangaroo humerus at the $70 \%$ length level, where a lateral flange and medial strut overlap the shaft in the radiograph, making it difficult to define the true shaft. This measurement was therefore not used in the full analysis. Other sites of higher measurement error were usually because a tuberosity created a large difference between two readings despite only a tiny misplacement in the measurement site (for example, the lateral cortical thickness of the dog humerus at the $30 \%$ length level); or a blending of cancellous bone and cortical bone at the site caused problems in delineating the cortical bone.

Slightly higher measurement errors might be expected for bones radiographed a second time, as there is the possibility of slight changes in position as well as defining the cortices a second time. As the percentage errors were still reasonably low (Table 2 part b), this indicates that the method is quite reproducible for almost all measurement sites. There was the occasional large error due to the reasons 
outlined above; and human bones often had larger errors than the non-human bones, possibly because the endosteal borders on human bones were often harder to define.

Although measurements of the shaft had acceptably low percentage errors in the interobserver error test (Table 2 part c), some of the percentage errors for the cortical bone thickness were greater than ideal. This was thought to be due to a different interpretation of the definition of "cortical bone", and highlights the need for specific instructions that cover many possible variations, which is frequently absent from previous works using radiogrammetry.

\begin{tabular}{llcccc}
\hline & & Mean (\%) & Median (\%) & Highest (\%) & Lowest (\%) \\
\hline $\begin{array}{l}\text { a) Second } \\
\text { measurement of } \\
\text { same x-ray }\end{array}$ & Shaft & 0.35 & 0.16 & 27.41 & 0.00 \\
& Cortical bone thickness & 2.20 & 1.01 & 75.19 & 0.00 \\
\hline b) Second & Shaft & 0.77 & 0.47 & 6.40 & 0.00 \\
x-ray & Cortical bone thickness & 3.13 & 1.68 & 69.03 & 0.00 \\
\hline c) Second & Shaft & 1.30 & 1.01 & 33.16 & 0.00 \\
observer & Cortical bone thickness & 5.61 & 3.51 & 79.82 & 0.00 \\
\hline
\end{tabular}

Table 2. Percentage measurement errors for intraobserver error tests ( $a$ and $b$ ) and interobserver error tests (c).

\section{Shaft diameter}

Table 3 shows the mean shaft diameters at each measurement site for the human samples only (nonhuman data not shown). For the humerus, sheep were the non-human group closest in diameter to humans, though overall the humans were more consistent in diameter from end of the shaft to the other than the non-human groups. For all groups studied, the radius was flattened in the anteroposterior direction along the length of the shaft, resulting in a greater mediolateral shaft diameter than anteroposterior shaft diameter. Additionally, it should be noted that kangaroos can be larger in size than those studied here, and the radii of these large kangaroos are very similar in size to those of humans, and worthy of further study. For the femur, the shaft diameter of the juvenile pig group was closest to the human groups. In all groups this bone was a relatively straight-sided, cylindrical shape, although the shafts of the cattle and pig femora expand towards each end. In the tibia, the anterior border resulted in a greater anteroposterior shaft diameter at the $30 \%$ length level for all groups. This greater anteroposterior diameter was maintained down the shaft for the human groups, whereas in the more distal measurements sites, the mediolateral diameter was greatest in the sheep, juvenile pigs and cattle. 


\begin{tabular}{|c|c|c|c|c|c|c|}
\hline \multirow{2}{*}{$\begin{array}{l}\text { Skeletal } \\
\text { element }\end{array}$} & \multirow{2}{*}{$\begin{array}{l}\text { Length } \\
\text { level }\end{array}$} & \multirow{2}{*}{ Group } & \multicolumn{2}{|c|}{ Mediolateral shaft } & \multicolumn{2}{|c|}{ Anteroposterior shaft } \\
\hline & & & Diameter (mm) & SD & Diameter (mm) & $\mathrm{SD}$ \\
\hline \multirow[t]{10}{*}{ Humerus } & \multirow[t]{2}{*}{$30 \%$} & Human male & 21.61 & 2.23 & 22.92 & 2.94 \\
\hline & & Human female & 18.30 & 1.77 & 17.92 & 1.78 \\
\hline & \multirow[t]{2}{*}{$40 \%$} & Human male & 21.98 & 2.42 & 22.18 & 2.78 \\
\hline & & Human female & 19.07 & 2.03 & 17.82 & 1.73 \\
\hline & \multirow[t]{2}{*}{$50 \%$} & Human male & 20.86 & 2.22 & 21.22 & 2.48 \\
\hline & & Human female & 17.50 & 1.98 & 18.13 & 1.68 \\
\hline & \multirow[t]{2}{*}{$60 \%$} & Human male & 19.37 & 1.90 & 21.47 & 2.09 \\
\hline & & Human female & 16.01 & 1.09 & 18.31 & 1.45 \\
\hline & \multirow[t]{2}{*}{$70 \%$} & Human male & 20.81 & 2.32 & 20.54 & 1.97 \\
\hline & & Human female & 16.86 & 1.47 & 17.60 & 1.23 \\
\hline \multirow[t]{10}{*}{ Radius } & \multirow[t]{2}{*}{$30 \%$} & Human male & 14.94 & 1.69 & 12.37 & 1.16 \\
\hline & & Human female & 12.72 & 1.31 & 10.41 & 0.89 \\
\hline & \multirow{2}{*}{$40 \%$} & Human male & 16.60 & 1.77 & 11.91 & 1.01 \\
\hline & & Human female & 14.81 & 1.23 & 9.97 & 0.73 \\
\hline & \multirow[t]{2}{*}{$50 \%$} & Human male & 15.86 & 1.76 & 12.24 & 1.14 \\
\hline & & Human female & 13.74 & 1.28 & 10.19 & 0.87 \\
\hline & \multirow[t]{2}{*}{$60 \%$} & Human male & 14.80 & 1.51 & 11.55 & 1.12 \\
\hline & & Human female & 12.29 & 1.07 & 9.70 & 0.85 \\
\hline & \multirow[t]{2}{*}{$70 \%$} & Human male & 15.64 & 1.53 & 11.53 & 1.06 \\
\hline & & Human female & 12.87 & 1.03 & 9.68 & 0.90 \\
\hline \multirow[t]{10}{*}{ Femur } & \multirow[t]{2}{*}{$30 \%$} & Human male & 29.80 & 3.20 & 27.11 & 2.22 \\
\hline & & Human female & 27.42 & 3.47 & 24.20 & 2.20 \\
\hline & \multirow[t]{2}{*}{$40 \%$} & Human male & 28.13 & 2.88 & 27.69 & 2.30 \\
\hline & & Human female & 25.77 & 2.91 & 25.10 & 2.16 \\
\hline & \multirow[t]{2}{*}{$50 \%$} & Human male & 27.43 & 2.53 & 28.14 & 2.52 \\
\hline & & Human female & 25.36 & 2.50 & 25.95 & 2.37 \\
\hline & \multirow[t]{2}{*}{$60 \%$} & Human male & 27.97 & 2.68 & 28.15 & 2.47 \\
\hline & & Human female & 25.89 & 2.52 & 25.81 & 2.12 \\
\hline & \multirow[t]{2}{*}{$70 \%$} & Human male & 30.58 & 3.54 & 28.60 & 2.46 \\
\hline & & Human female & 28.76 & 2.90 & 25.53 & 1.83 \\
\hline \multirow[t]{10}{*}{ Tibia } & \multirow[t]{2}{*}{$30 \%$} & Human male & 24.45 & 2.59 & 34.69 & 3.34 \\
\hline & & Human female & 21.13 & 2.01 & 30.39 & 1.94 \\
\hline & $40 \%$ & Human male & 23.06 & 2.31 & 31.70 & 2.83 \\
\hline & & Human female & 19.88 & 1.83 & 27.32 & 1.56 \\
\hline & $50 \%$ & Human male & 21.84 & 2.06 & 29.44 & 2.80 \\
\hline & & Human female & 18.91 & 1.71 & 25.59 & 1.70 \\
\hline & $60 \%$ & Human male & 20.60 & 1.96 & 26.87 & 2.68 \\
\hline & & Human female & 18.35 & 1.82 & 23.40 & 1.79 \\
\hline & $70 \%$ & Human male & 20.94 & 1.98 & 25.00 & 2.75 \\
\hline & & Human female & 18.61 & 1.84 & $21.88^{a}$ & 1.67 \\
\hline
\end{tabular}

Table 3. Shaft diameter: mean and one standard deviation (SD) for each orientation at each length level for all human skeletal elements. $n=25$ except ${ }^{a} n=24$ for that variable in that sample.

Cortical bone thickness - humerus

Table 4 shows the mean cortical bone thickness, for each aspect and length level of the humerus.

Human humerus cortical bone thickness values were comparatively similar throughout the shaft. 


\begin{tabular}{|c|c|c|c|c|c|c|c|c|c|c|}
\hline \multirow{2}{*}{$\begin{array}{l}\text { Length } \\
\text { level }\end{array}$} & \multirow{2}{*}{ Group } & \multirow[b]{2}{*}{$n$} & \multicolumn{2}{|c|}{ Medial } & \multicolumn{2}{|c|}{ Lateral } & \multicolumn{2}{|c|}{ Anterior } & \multicolumn{2}{|c|}{ Posterior } \\
\hline & & & Cortex & $\mathrm{SD}$ & Cortex & $\mathrm{SD}$ & Cortex & $\mathrm{SD}$ & Cortex & SD \\
\hline \multirow[t]{7}{*}{$30 \%$} & Kangaroo & 9 & 1.66 & 0.17 & $2.57^{\mathrm{a}}$ & 1.24 & 1.33 & 0.31 & 2.11 & 0.19 \\
\hline & Sheep & 24 & 2.45 & 0.45 & 2.26 & 0.43 & 2.51 & 0.81 & 2.48 & 0.47 \\
\hline & Pig (juvenile) & 18 & 3.05 & 0.56 & 1.99 & 0.84 & 2.54 & 0.72 & 2.74 & 0.56 \\
\hline & Dog (greyhound) & 19 & 2.25 & 0.32 & 3.00 & 1.25 & 2.39 & 0.25 & 2.80 & 0.37 \\
\hline & Cattle & 29 & 5.76 & 1.07 & 4.85 & 1.28 & $3.40^{b}$ & 2.33 & 4.70 & 0.73 \\
\hline & Human male & 25 & 3.15 & 0.56 & 2.86 & 0.45 & 4.03 & 0.81 & 2.97 & 0.62 \\
\hline & Human female & 25 & 2.81 & 0.58 & 2.64 & 0.72 & 3.19 & 1.08 & 2.60 & 0.68 \\
\hline \multirow[t]{7}{*}{$40 \%$} & Kangaroo & 9 & 2.43 & 0.47 & 1.76 & 0.82 & 1.88 & 0.63 & 2.40 & 0.44 \\
\hline & Sheep & 24 & 3.15 & 0.67 & 2.40 & 0.41 & 3.06 & 0.54 & 2.69 & 0.54 \\
\hline & Pig (juvenile) & 18 & 4.87 & 0.79 & 2.75 & 0.57 & 4.95 & 0.96 & 3.76 & 0.51 \\
\hline & Dog (greyhound) & 19 & 2.49 & 0.20 & 1.93 & 0.37 & 2.68 & 0.46 & 2.66 & 0.27 \\
\hline & Cattle & 29 & 8.46 & 1.48 & 5.77 & 0.93 & 6.10 & 1.48 & 7.00 & 1.78 \\
\hline & Human male & 25 & 3.86 & 0.72 & 3.37 & 1.01 & 3.91 & 1.07 & 3.30 & 0.85 \\
\hline & Human female & 25 & 3.14 & 0.87 & 2.73 & 1.15 & 3.11 & 1.01 & 2.92 & 0.97 \\
\hline \multirow[t]{7}{*}{$50 \%$} & Kangaroo & 9 & 2.64 & 0.57 & 2.53 & 0.63 & 3.16 & 2.38 & 2.35 & 0.48 \\
\hline & Sheep & 24 & 3.61 & 0.65 & 2.83 & 0.47 & 3.22 & 0.61 & 3.73 & 0.97 \\
\hline & Pig (juvenile) & 18 & 5.42 & 0.85 & 3.58 & 0.40 & 7.95 & 1.34 & 5.69 & 0.77 \\
\hline & Dog (greyhound) & 19 & 2.64 & 0.20 & 2.44 & 0.33 & 2.58 & 0.39 & 2.74 & 0.35 \\
\hline & Cattle & 29 & 11.53 & 2.16 & 6.21 & 0.97 & 8.72 & 1.48 & 10.31 & 2.39 \\
\hline & Human male & 25 & 4.32 & 0.83 & 4.09 & 1.06 & 3.82 & 0.91 & 3.73 & 0.82 \\
\hline & Human female & 25 & 3.34 & 0.84 & 3.13 & 0.84 & 3.43 & 1.04 & 2.97 & 0.92 \\
\hline \multirow[t]{7}{*}{$60 \%$} & Kangaroo & 9 & 3.31 & 0.76 & 2.86 & 0.67 & 3.40 & 0.83 & 2.38 & 0.67 \\
\hline & Sheep & 24 & 3.48 & 0.61 & 2.88 & 0.67 & 3.25 & 0.62 & 3.47 & 0.90 \\
\hline & Pig (juvenile) & 18 & 5.02 & 0.72 & 4.14 & 0.50 & 8.90 & 1.70 & 5.72 & 1.57 \\
\hline & Dog (greyhound) & 19 & 3.01 & 0.27 & 2.67 & 0.26 & 3.03 & 0.42 & 3.31 & 0.47 \\
\hline & Cattle & 29 & 10.66 & 1.88 & 7.03 & 1.27 & 11.83 & 2.02 & 10.11 & 2.28 \\
\hline & Human male & 25 & 4.25 & 1.03 & 4.06 & 0.59 & 4.67 & 0.92 & 3.99 & 1.00 \\
\hline & Human female & 25 & 3.31 & 0.82 & 3.23 & 0.90 & 3.78 & 0.94 & 2.83 & 0.71 \\
\hline \multirow[t]{7}{*}{$70 \%$} & Kangaroo & 9 & 3.03 & 0.49 & - & - & 2.84 & 0.66 & $2.65^{\mathrm{a}}$ & 0.99 \\
\hline & Sheep & 24 & 3.72 & 0.71 & 2.98 & 0.90 & 3.94 & 0.79 & 3.68 & 0.88 \\
\hline & Pig (juvenile) & 18 & 3.64 & 0.50 & 3.73 & 0.52 & 6.98 & 1.86 & 3.84 & 1.08 \\
\hline & Dog (greyhound) & 19 & 2.79 & 0.23 & 2.48 & 0.25 & 3.20 & 0.50 & 3.05 & 0.42 \\
\hline & Cattle & 29 & 10.07 & 2.07 & 8.60 & 1.96 & $13.06^{\mathrm{c}}$ & 2.75 & $9.34^{c}$ & 2.33 \\
\hline & Human male & 25 & 4.24 & 0.66 & 4.70 & 1.36 & 4.68 & 0.78 & 3.66 & 1.06 \\
\hline & Human female & 25 & 3.23 & 0.85 & 3.20 & 0.87 & 3.47 & 0.75 & 2.74 & 0.72 \\
\hline
\end{tabular}

Table 4. Humerus cortical bone thickness: mean and one standard deviation (SD) for all length levels of all taxa. Measurements in millimetres. ${ }^{\mathrm{a}} n=8,{ }^{\mathrm{b}} n=28,{ }^{\mathrm{c}} n=22$ for that variable in that sample.

Table 5 shows the results of t-tests conducted between the sex-separated human groups and each of the non-human groups in turn. The kangaroo group was not analysed statistically as the specimens were few in number, although the unusual shape of the kangaroo humerus renders it morphologically quite dissimilar to the human bone at almost all points along its shaft. Cortical bone thickness in the human groups was significantly less than almost all corresponding cattle measurement sites, mostly less than those for juvenile pig, and mostly greater than those for greyhound dog. The comparison with sheep showed some mixed results, with several sheep measurement sites significantly less than those of humans, several showing no difference, and a few actually greater than the corresponding human site. 


\begin{tabular}{|c|c|c|c|c|c|}
\hline $\begin{array}{l}\text { Cortical thickness } \\
\text { and length level }\end{array}$ & Human group & Sheep & $\begin{array}{r}\text { Pig } \\
\text { juvenile }\end{array}$ & $\begin{array}{r}\text { Dog } \\
\text { greyhound }\end{array}$ & Cattle \\
\hline \multirow{2}{*}{ Medial 30\% } & Human male & $<0.001$ & 0.553 & $<0.001$ & $<0.001$ \\
\hline & Human female & 0.017 & 0.193 & $<0.001$ & $<0.001$ \\
\hline \multirow[t]{2}{*}{ Lateral $30 \%$} & Human male & $<0.001$ & $<0.001$ & 0.582 & $<0.001$ \\
\hline & Human female & 0.030 & 0.009 & 0.220 & $<0.001$ \\
\hline \multirow[t]{2}{*}{ Anterior $30 \%$} & Human male & $<0.001$ & $<0.001$ & $<0.001$ & $<0.001$ \\
\hline & Human female & 0.015 & 0.031 & 0.003 & 0.468 \\
\hline \multirow[t]{2}{*}{ Posterior $30 \%$} & Human male & 0.003 & 0.214 & 0.288 & $<0.001$ \\
\hline & Human female & 0.487 & 0.479 & 0.254 & $<0.001$ \\
\hline \multirow[t]{2}{*}{ Medial $40 \%$} & Human male & 0.001 & $<0.001$ & $<0.001$ & $<0.001$ \\
\hline & Human female & 0.977 & $<0.001$ & 0.003 & $<0.001$ \\
\hline \multirow[t]{2}{*}{ Lateral $40 \%$} & Human male & $<0.001$ & 0.026 & $<0.001$ & $<0.001$ \\
\hline & Human female & 0.185 & 0.948 & $<0.001$ & $<0.001$ \\
\hline \multirow[t]{2}{*}{ Anterior $40 \%$} & Human male & 0.001 & 0.002 & $<0.001$ & $<0.001$ \\
\hline & Human female & 0.820 & $<0.001$ & 0.087 & $<0.001$ \\
\hline \multirow[t]{2}{*}{ Posterior $40 \%$} & Human male & 0.005 & 0.045 & 0.003 & $<0.001$ \\
\hline & Human female & 0.310 & 0.002 & 0.257 & $<0.001$ \\
\hline \multirow[t]{2}{*}{ Medial 50\% } & Human male & 0.002 & $<0.001$ & $<0.001$ & $<0.001$ \\
\hline & Human female & 0.223 & $<0.001$ & 0.001 & $<0.001$ \\
\hline \multirow[t]{2}{*}{ Lateral $50 \%$} & Human male & $<0.001$ & 0.056 & $<0.001$ & $<0.001$ \\
\hline & Human female & 0.127 & 0.046 & 0.002 & $<0.001$ \\
\hline \multirow[t]{2}{*}{ Anterior $50 \%$} & Human male & 0.009 & $<0.001$ & $<0.001$ & $<0.001$ \\
\hline & Human female & 0.401 & $<0.001$ & 0.002 & $<0.001$ \\
\hline \multirow[t]{2}{*}{ Posterior 50\% } & Human male & 0.996 & $<0.001$ & $<0.001$ & $<0.001$ \\
\hline & Human female & 0.007 & $<0.001$ & 0.305 & $<0.001$ \\
\hline \multirow[t]{2}{*}{ Medial 60\% } & Human male & 0.003 & 0.009 & $<0.001$ & $<0.001$ \\
\hline & Human female & 0.439 & $<0.001$ & 0.125 & $<0.001$ \\
\hline \multirow[t]{2}{*}{ Lateral $60 \%$} & Human male & $<0.001$ & 0.617 & $<0.001$ & $<0.001$ \\
\hline & Human female & 0.132 & $<0.001$ & 0.012 & $<0.001$ \\
\hline \multirow[t]{2}{*}{ Anterior $60 \%$} & Human male & $<0.001$ & $<0.001$ & $<0.001$ & $<0.001$ \\
\hline & Human female & 0.025 & $<0.001$ & 0.002 & $<0.001$ \\
\hline \multirow[t]{2}{*}{ Posterior $60 \%$} & Human male & 0.064 & $<0.001$ & 0.010 & $<0.001$ \\
\hline & Human female & 0.008 & $<0.001$ & 0.013 & $<0.001$ \\
\hline \multirow[t]{2}{*}{ Medial $70 \%$} & Human male & 0.010 & 0.002 & $<0.001$ & $<0.001$ \\
\hline & Human female & 0.034 & 0.072 & 0.057 & $<0.001$ \\
\hline \multirow[t]{2}{*}{ Lateral $70 \%$} & Human male & $<0.001$ & 0.006 & $<0.001$ & $<0.001$ \\
\hline & Human female & 0.389 & 0.026 & 0.001 & $<0.001$ \\
\hline \multirow[t]{2}{*}{ Anterior $70 \%$} & Human male & 0.002 & $<0.001$ & $<0.001$ & $<0.001$ \\
\hline & Human female & 0.035 & $<0.001$ & 0.188 & $<0.001$ \\
\hline \multirow[t]{2}{*}{ Posterior $70 \%$} & Human male & 0.943 & 0.577 & 0.022 & $<0.001$ \\
\hline & Human female & $<0.001$ & $<0.001$ & 0.107 & $<0.001$ \\
\hline
\end{tabular}

Table 5. Humerus cortical bone thickness: $p$ values from t-tests; values below 0.05 indicate significant difference. Bold type = human group is significantly greater than non-human group; italic type = human group is significantly less than non-human group.

\section{Cortical bone thickness - radius}

The cortical bone thickness (Table 6) in humans is much greater at the medial aspect due to the prominent, sharp interosseous border. This is a point of difference between the human and kangaroo radii, as the kangaroo interosseous border is much less pronounced. The morphology of the juvenile pig radii meant that some cortices could not be measured accurately, as radiographically it was too 
difficult to discern what was actual cortical bone. Dense ridges towards the medial and lateral sides obscured the posterior cortical bone thickness, and a mass of bone internally on the lateral side did not appear to fit either category of cortical or cancellous bone, so was not recorded.

\begin{tabular}{|c|c|c|c|c|c|c|c|c|c|c|}
\hline \multicolumn{3}{|c|}{ Length } & \multicolumn{2}{|c|}{ Medial } & \multicolumn{2}{|c|}{ Lateral } & \multicolumn{2}{|c|}{ Anterior } & \multicolumn{2}{|c|}{ Posterior } \\
\hline level & Group & $n$ & Cortex & $\mathrm{SD}$ & Cortex & $\mathrm{SD}$ & Cortex & $\mathrm{SD}$ & Cortex & $\mathrm{SD}$ \\
\hline \multirow[t]{7}{*}{$30 \%$} & Kangaroo & 24 & 2.17 & 0.75 & 1.91 & 0.62 & 2.07 & 0.41 & 1.83 & 0.44 \\
\hline & Sheep & 27 & 6.98 & 1.19 & 4.54 & 0.83 & 2.83 & 0.42 & 3.24 & 0.58 \\
\hline & Pig (juvenile) & 22 & $2.45^{\mathrm{a}}$ & 0.95 & $3.65^{\mathrm{b}}$ & 0.90 & 2.51 & 0.45 & - & - \\
\hline & Dog (greyhound) & 22 & 4.69 & 0.62 & 3.41 & 0.73 & 2.27 & 0.25 & 2.99 & 0.57 \\
\hline & Cattle & 28 & 13.18 & 2.05 & 9.93 & 1.54 & 6.69 & 1.07 & 5.36 & 0.90 \\
\hline & Human male & 25 & 3.67 & 1.13 & 2.77 & 0.53 & 3.22 & 0.68 & 2.67 & 0.60 \\
\hline & Human female & 25 & 2.94 & 1.09 & 2.32 & 0.54 & 2.60 & 0.82 & 2.05 & 0.60 \\
\hline \multirow[t]{7}{*}{$40 \%$} & Kangaroo & 24 & 2.09 & 0.60 & 2.16 & 0.51 & 1.92 & 0.30 & 1.94 & 0.45 \\
\hline & Sheep & 27 & 6.15 & 0.96 & 4.64 & 0.91 & 2.97 & 0.32 & 3.12 & 0.55 \\
\hline & Pig (juvenile) & 22 & $3.44^{\mathrm{c}}$ & 1.04 & - & - & 2.66 & 0.36 & - & - \\
\hline & Dog (greyhound) & 22 & 4.27 & 0.52 & 3.35 & 0.66 & 2.43 & 0.26 & 2.72 & 0.49 \\
\hline & Cattle & 28 & 13.96 & 1.93 & 9.82 & 1.38 & 6.17 & 0.82 & 5.33 & 0.71 \\
\hline & Human male & 25 & 5.99 & 1.41 & 3.00 & 0.46 & 3.52 & 0.59 & 3.60 & 0.57 \\
\hline & Human female & 25 & 5.24 & 1.09 & 2.44 & 0.58 & 2.74 & 0.83 & 2.89 & 0.63 \\
\hline \multirow[t]{7}{*}{$50 \%$} & Kangaroo & 24 & 2.01 & 0.44 & 2.11 & 0.39 & 1.87 & 0.28 & 2.04 & 0.43 \\
\hline & Sheep & 27 & 5.18 & 0.61 & 4.57 & 0.73 & 2.91 & 0.28 & 2.85 & 0.54 \\
\hline & Pig (juvenile) & 22 & 3.26 & 0.80 & - & - & 2.35 & 0.32 & - & - \\
\hline & Dog (greyhound) & 22 & 3.99 & 0.50 & 3.33 & 0.54 & 2.45 & 0.24 & 2.67 & 0.39 \\
\hline & Cattle & 28 & 10.66 & 1.46 & 8.49 & 1.01 & 5.35 & 0.66 & 4.49 & 0.67 \\
\hline & Human male & 25 & 5.58 & 1.11 & 3.24 & 0.70 & 3.41 & 0.59 & 3.79 & 0.62 \\
\hline & Human female & 25 & 5.02 & 0.79 & 2.32 & 0.73 & 2.77 & 0.79 & 2.97 & 0.70 \\
\hline \multirow[t]{7}{*}{$60 \%$} & Kangaroo & 24 & 1.89 & 0.48 & 2.05 & 0.34 & 1.79 & 0.30 & 1.89 & 0.36 \\
\hline & Sheep & 27 & 4.08 & 0.60 & 4.03 & 0.63 & 2.84 & 0.36 & 2.74 & 0.48 \\
\hline & Pig (juvenile) & 22 & 2.78 & 0.51 & - & - & 2.12 & 0.24 & - & - \\
\hline & Dog (greyhound) & 22 & 3.53 & 0.43 & 3.63 & 0.71 & 2.56 & 0.23 & 2.58 & 0.48 \\
\hline & Cattle & 28 & 7.70 & 1.27 & 6.31 & 0.99 & 4.70 & 0.49 & 3.78 & 0.63 \\
\hline & Human male & 25 & 4.35 & 0.93 & 3.12 & 0.59 & 3.20 & 0.48 & 3.21 & 0.50 \\
\hline & Human female & 25 & 3.63 & 0.60 & 2.47 & 0.71 & 2.67 & 0.66 & 2.53 & 0.69 \\
\hline \multirow[t]{7}{*}{$70 \%$} & Kangaroo & 24 & 1.65 & 0.37 & 1.85 & 0.30 & 1.66 & 0.30 & 1.73 & 0.31 \\
\hline & Sheep & 27 & 3.59 & 0.48 & 3.42 & 0.47 & 2.67 & 0.35 & 2.65 & 0.51 \\
\hline & Pig (juvenile) & 22 & 1.99 & 0.36 & $2.15^{\mathrm{c}}$ & 0.43 & 1.43 & 0.24 & - & - \\
\hline & Dog (greyhound) & 22 & 3.05 & 0.35 & 3.97 & 1.00 & 2.42 & 0.24 & 2.46 & 0.31 \\
\hline & Cattle & 28 & 4.85 & 1.08 & $4.11^{\mathrm{d}}$ & 0.99 & 3.20 & 0.60 & 3.58 & 0.95 \\
\hline & Human male & 25 & 3.48 & 0.47 & 2.70 & 0.56 & 2.77 & 0.37 & 2.91 & 0.39 \\
\hline & Human female & 25 & 3.07 & 0.55 & 2.14 & 0.69 & 2.17 & 0.50 & 2.32 & 0.55 \\
\hline
\end{tabular}

Table 6. Radius cortical bone thickness: mean and standard deviation (SD) for all length levels of all groups. Measurements in millimetres. ${ }^{\mathrm{a}} n=20,{ }^{\mathrm{b}} n=17,{ }^{\mathrm{c}} n=21,{ }^{\mathrm{d}} n=27$ for that variable in that sample.

Human cortical bone thickness in the radius was significantly greater than kangaroo and juvenile pig for almost all measurement sites, and less than cattle for all measurement sites (Table 7). Results were mixed for sheep and greyhound dog. 


\begin{tabular}{|c|c|c|c|c|c|c|}
\hline $\begin{array}{l}\text { Cortical thickness } \\
\text { and length level }\end{array}$ & Human group & Kangaroo & Sheep & $\begin{array}{c}\text { Pig } \\
\text { juvenile }\end{array}$ & $\begin{array}{l}\text { Dog } \\
\text { greyhound }\end{array}$ & Cattle \\
\hline \multirow[t]{2}{*}{ Medial 30\% } & Human male & $<0.001$ & $<0.001$ & $<0.001$ & $<0.001$ & $<0.001$ \\
\hline & Human female & 0.006 & $<0.001$ & 0.117 & $<0.001$ & $<0.001$ \\
\hline \multirow[t]{2}{*}{ Lateral $30 \%$} & Human male & $<0.001$ & $<0.001$ & $<0.001$ & 0.001 & $<0.001$ \\
\hline & Human female & 0.016 & $<0.001$ & $<0.001$ & $<0.001$ & $<0.001$ \\
\hline \multirow[t]{2}{*}{ Anterior $30 \%$} & Human male & 0.007 & 0.014 & $<0.001$ & $<0.001$ & $<0.001$ \\
\hline & Human female & $<0.001$ & 0.203 & 0.675 & 0.081 & $<0.001$ \\
\hline \multirow[t]{2}{*}{ Posterior $30 \%$} & Human male & $<0.001$ & 0.001 & - & 0.071 & $<0.001$ \\
\hline & Human female & 0.167 & $<0.001$ & - & $<0.001$ & $<0.001$ \\
\hline \multirow[t]{2}{*}{ Medial 40\% } & Human male & $<0.001$ & 0.619 & $<0.001$ & $<0.001$ & $<0.001$ \\
\hline & Human female & $<0.001$ & 0.002 & $<0.001$ & $<0.001$ & $<0.001$ \\
\hline \multirow[t]{2}{*}{ Lateral $40 \%$} & Human male & $<0.001$ & $<0.001$ & - & 0.033 & $<0.001$ \\
\hline & Human female & 0.079 & $<0.001$ & - & $<0.001$ & $<0.001$ \\
\hline \multirow[t]{2}{*}{ Anterior $40 \%$} & Human male & $<0.001$ & $<0.001$ & $<0.001$ & $<0.001$ & $<0.001$ \\
\hline & Human female & $<0.001$ & 0.187 & 0.686 & 0.098 & $<0.001$ \\
\hline \multirow[t]{2}{*}{ Posterior $40 \%$} & Human male & $<0.001$ & 0.003 & - & $<0.001$ & $<0.001$ \\
\hline & Human female & $<0.001$ & 0.159 & - & 0.332 & $<0.001$ \\
\hline \multirow[t]{2}{*}{ Medial 50\% } & Human male & $<0.001$ & 0.114 & $<0.001$ & $<0.001$ & $<0.001$ \\
\hline & Human female & $<0.001$ & 0.412 & $<0.001$ & $<0.001$ & $<0.001$ \\
\hline \multirow[t]{2}{*}{ Lateral $50 \%$} & Human male & $<0.001$ & $<0.001$ & - & 0.608 & $<0.001$ \\
\hline & Human female & 0.210 & $<0.001$ & - & $<0.001$ & $<0.001$ \\
\hline \multirow[t]{2}{*}{ Anterior $50 \%$} & Human male & $<0.001$ & $<0.001$ & $<0.001$ & $<0.001$ & $<0.001$ \\
\hline & Human female & $<0.001$ & 0.372 & 0.024 & 0.077 & $<0.001$ \\
\hline \multirow[t]{2}{*}{ Posterior 50\% } & Human male & $<0.001$ & $<0.001$ & - & $<0.001$ & $<0.001$ \\
\hline & Human female & $<0.001$ & 0.483 & - & 0.082 & $<0.001$ \\
\hline \multirow[t]{2}{*}{ Medial 60\% } & Human male & $<0.001$ & 0.205 & $<0.001$ & $<0.001$ & $<0.001$ \\
\hline & Human female & $<0.001$ & 0.009 & $<0.001$ & 0.531 & $<0.001$ \\
\hline \multirow[t]{2}{*}{ Lateral $60 \%$} & Human male & $<0.001$ & $<0.001$ & - & 0.010 & $<0.001$ \\
\hline & Human female & 0.012 & $<0.001$ & - & $<0.001$ & $<0.001$ \\
\hline \multirow[t]{2}{*}{ Anterior $60 \%$} & Human male & $<0.001$ & 0.004 & $<0.001$ & $<0.001$ & $<0.001$ \\
\hline & Human female & $<0.001$ & 0.234 & 0.001 & 0.482 & $<0.001$ \\
\hline \multirow[t]{2}{*}{ Posterior $60 \%$} & Human male & $<0.001$ & 0.001 & - & $<0.001$ & 0.001 \\
\hline & Human female & $<0.001$ & 0.195 & - & 0.754 & $<0.001$ \\
\hline \multirow[t]{2}{*}{ Medial 70\% } & Human male & $<0.001$ & 0.423 & $<0.001$ & 0.001 & $<0.001$ \\
\hline & Human female & $<0.001$ & 0.001 & $<0.001$ & 0.922 & $<0.001$ \\
\hline \multirow[t]{2}{*}{ Lateral $70 \%$} & Human male & $<0.001$ & $<0.001$ & 0.001 & $<0.001$ & $<0.001$ \\
\hline & Human female & 0.065 & $<0.001$ & 0.957 & $<0.001$ & $<0.001$ \\
\hline \multirow[t]{2}{*}{ Anterior $70 \%$} & Human male & $<0.001$ & 0.295 & $<0.001$ & $<0.001$ & 0.004 \\
\hline & Human female & $<0.001$ & $<0.001$ & $<0.001$ & 0.047 & $<0.001$ \\
\hline \multirow[t]{2}{*}{ Posterior $70 \%$} & Human male & $<0.001$ & 0.041 & - & $<0.001$ & 0.002 \\
\hline & Human female & $<0.001$ & 0.028 & - & 0.284 & $<0.001$ \\
\hline
\end{tabular}

Table 7. Radius cortical bone thickness: $p$ values from t-tests; values below 0.05 indicate significant difference. Bold type $=$ human group is significantly greater than non-human group; italic type $=$ human group is significantly less than non-human group.

\section{Cortical bone thickness - femur}

The comparative cortical bone thickness measurements (Table 8) are quite consistent throughout the femoral shaft for the sheep and greyhound dog. In the human, the figures for posterior cortical bone thickness tend to be greatest partly due to the inclusion of the linea aspera, which cannot be avoided in radiographs. However, medial and lateral cortices were also considerable in thickness. The increase in 
posterior cortical bone thickness at the $40 \%$ length level in the kangaroo is due to a distinct, bulging tuberosity at this point.

\begin{tabular}{|c|c|c|c|c|c|c|c|c|c|c|}
\hline \multicolumn{3}{|c|}{ Length } & \multicolumn{2}{|c|}{ Medial } & \multicolumn{2}{|c|}{ Lateral } & \multicolumn{2}{|c|}{ Anterior } & \multicolumn{2}{|c|}{ Posterior } \\
\hline level & Group & $n$ & Cortex & SD & Cortex & SD & Cortex & SD & Cortex & SD \\
\hline \multirow[t]{7}{*}{$30 \%$} & Kangaroo & 30 & 3.79 & 0.74 & 3.12 & 0.49 & 4.09 & 0.84 & 3.64 & 0.62 \\
\hline & Sheep & 28 & 2.66 & 0.41 & 2.20 & 0.34 & 2.75 & 0.39 & 2.74 & 0.64 \\
\hline & Pig (juvenile) & 27 & 4.42 & 0.72 & 2.75 & 0.82 & 4.32 & 1.09 & 3.43 & 0.57 \\
\hline & Dog (greyhound) & 17 & 2.57 & 0.27 & 2.38 & 0.26 & 2.68 & 0.26 & 2.39 & 0.26 \\
\hline & Cattle & 24 & 6.60 & 1.42 & 6.84 & 1.14 & 8.39 & 1.94 & 6.31 & 1.38 \\
\hline & Human male & 25 & 7.67 & 1.67 & 7.43 & 1.49 & $4.67^{\mathrm{a}}$ & 1.04 & $5.87^{\mathrm{a}}$ & 1.53 \\
\hline & Human female & 25 & 6.67 & 1.56 & 6.38 & 1.55 & 4.01 & 1.23 & $4.78^{b}$ & 1.21 \\
\hline \multirow[t]{7}{*}{$40 \%$} & Kangaroo & 30 & 3.81 & 0.72 & 3.56 & 0.61 & 3.92 & 0.79 & 5.16 & 1.12 \\
\hline & Sheep & 28 & 3.23 & 0.54 & 2.66 & 0.57 & 3.07 & 0.48 & 2.78 & 0.70 \\
\hline & Pig (juvenile) & 27 & 4.21 & 0.76 & 4.20 & 0.93 & 4.78 & 0.86 & 5.37 & 1.12 \\
\hline & Dog (greyhound) & 17 & 2.70 & 0.28 & 2.44 & 0.22 & 2.68 & 0.32 & 2.52 & 0.30 \\
\hline & Cattle & 24 & 8.56 & 1.71 & 7.87 & 1.39 & 9.96 & 2.06 & 7.66 & 1.22 \\
\hline & Human male & 25 & 7.92 & 1.75 & 7.56 & 1.44 & 5.25 & 1.13 & 7.15 & 1.77 \\
\hline & Human female & 25 & 6.65 & 1.69 & 6.70 & 1.42 & 4.13 & 1.18 & $6.47^{\mathrm{b}}$ & 2.11 \\
\hline \multirow[t]{7}{*}{$50 \%$} & Kangaroo & 30 & 3.86 & 0.74 & 3.47 & 0.53 & 3.96 & 0.74 & 4.21 & 0.80 \\
\hline & Sheep & 28 & 3.13 & 0.64 & 2.69 & 0.61 & 3.15 & 0.57 & 2.53 & 0.68 \\
\hline & Pig (juvenile) & 27 & 3.96 & 0.40 & 5.06 & 0.97 & 4.65 & 0.94 & 5.72 & 1.07 \\
\hline & Dog (greyhound) & 17 & 2.44 & 0.16 & 2.39 & 0.20 & 2.39 & 0.28 & 2.59 & 0.26 \\
\hline & Cattle & 24 & 8.08 & 1.30 & 8.67 & 1.65 & 8.94 & 1.84 & 7.90 & 1.46 \\
\hline & Human male & 25 & 7.21 & 1.45 & 7.17 & 1.31 & 5.04 & 1.01 & 7.86 & 1.21 \\
\hline & Human female & 25 & 6.10 & 1.55 & 6.03 & 1.20 & 3.87 & 1.12 & $7.90^{b}$ & 1.59 \\
\hline \multirow[t]{7}{*}{$60 \%$} & Kangaroo & 30 & 3.41 & 0.56 & 3.13 & 0.39 & 3.73 & 0.64 & 3.14 & 0.60 \\
\hline & Sheep & 28 & 2.80 & 0.44 & 2.70 & 0.62 & 3.29 & 0.73 & 2.73 & 0.61 \\
\hline & Pig (juvenile) & 27 & 3.30 & 0.33 & 5.50 & 1.23 & 3.10 & 0.53 & 3.89 & 0.59 \\
\hline & Dog (greyhound) & 17 & 2.46 & 0.23 & 2.30 & 0.23 & 2.26 & 0.31 & 2.58 & 0.34 \\
\hline & Cattle & 24 & 6.62 & 1.09 & 9.67 & 2.36 & 6.36 & 1.61 & 7.38 & 1.89 \\
\hline & Human male & 25 & 5.83 & 1.04 & 5.43 & 0.95 & 4.20 & 1.02 & 6.34 & 1.19 \\
\hline & Human female & 25 & 4.91 & 1.32 & 4.60 & 0.93 & 3.39 & 1.04 & $6.25^{\mathrm{b}}$ & 1.13 \\
\hline \multirow[t]{7}{*}{$70 \%$} & Kangaroo & 30 & 2.95 & 0.41 & 3.08 & 0.53 & 3.37 & 0.52 & 3.02 & 0.39 \\
\hline & Sheep & 28 & 2.66 & 0.43 & 2.94 & 0.63 & 2.87 & 0.55 & 2.90 & 0.72 \\
\hline & Pig (juvenile) & 27 & 2.95 & 0.46 & 3.34 & 0.53 & 2.32 & 0.54 & 3.00 & 0.69 \\
\hline & Dog (greyhound) & 17 & 2.36 & 0.27 & 2.06 & 0.24 & 2.18 & 0.30 & 2.40 & 0.48 \\
\hline & Cattle & 24 & 7.08 & 2.24 & 6.43 & 3.04 & 3.81 & 1.48 & $5.65^{\mathrm{b}}$ & 1.42 \\
\hline & Human male & 25 & 4.09 & 0.89 & 3.88 & 0.73 & 3.65 & 0.69 & 4.24 & 0.71 \\
\hline & Human female & 25 & 3.34 & 0.98 & 3.18 & 0.79 & 2.82 & 1.08 & 4.09 & 1.31 \\
\hline
\end{tabular}

Table 8. Femur cortical bone thickness: mean and standard deviation (SD) for all length levels of all groups. Measurements in millimetres. ${ }^{\mathrm{a}} n=24,{ }^{\mathrm{b}} n=23$ for that variable in that sample.

Overall, the thickness of human femoral cortical bone was statistically greater than the non-human groups at almost all measurements sites (Table 9), except for cattle where there was generally either no difference or the human measurements were significantly less. 


\begin{tabular}{|c|c|c|c|c|c|c|}
\hline $\begin{array}{l}\text { Cortical thickness } \\
\text { and length level }\end{array}$ & Human group & Kangaroo & Sheep & $\begin{array}{c}\text { Pig } \\
\text { juvenile }\end{array}$ & $\begin{array}{c}\text { Dog } \\
\text { greyhound }\end{array}$ & Cattle \\
\hline \multirow[t]{2}{*}{ Medial 30\% } & Human male & $<0.001$ & $<0.001$ & $<0.001$ & $<0.001$ & 0.020 \\
\hline & Human female & $<0.001$ & $<0.001$ & $<0.001$ & $<0.001$ & 0.873 \\
\hline \multirow[t]{2}{*}{ Lateral $30 \%$} & Human male & $<0.001$ & $<0.001$ & $<0.001$ & $<0.001$ & 0.132 \\
\hline & Human female & $<0.001$ & $<0.001$ & $<0.001$ & $<0.001$ & 0.242 \\
\hline \multirow[t]{2}{*}{ Anterior $30 \%$} & Human male & 0.028 & $<0.001$ & 0.249 & $<0.001$ & $<0.001$ \\
\hline & Human female & 0.765 & $<0.001$ & 0.335 & $<0.001$ & $<0.001$ \\
\hline \multirow[t]{2}{*}{ Posterior $30 \%$} & Human male & $<0.001$ & $<0.001$ & $<0.001$ & $<0.001$ & 0.298 \\
\hline & Human female & $<0.001$ & $<0.001$ & $<0.001$ & $<0.001$ & $<0.001$ \\
\hline \multirow[t]{2}{*}{ Medial $40 \%$} & Human male & $<0.001$ & $<0.001$ & $<0.001$ & $<0.001$ & 0.202 \\
\hline & Human female & $<0.001$ & $<0.001$ & $<0.001$ & $<0.001$ & $<0.001$ \\
\hline \multirow[t]{2}{*}{ Lateral $40 \%$} & Human male & $<0.001$ & $<0.001$ & $<0.001$ & $<0.001$ & 0.448 \\
\hline & Human female & $<0.001$ & $<0.001$ & $<0.001$ & $<0.001$ & 0.005 \\
\hline \multirow[t]{2}{*}{ Anterior $40 \%$} & Human male & $<0.001$ & $<0.001$ & 0.094 & $<0.001$ & $<0.001$ \\
\hline & Human female & 0.438 & $<0.001$ & 0.026 & $<0.001$ & $<0.001$ \\
\hline \multirow[t]{2}{*}{ Posterior $40 \%$} & Human male & $<0.001$ & $<0.001$ & $<0.001$ & $<0.001$ & 0.247 \\
\hline & Human female & 0.005 & $<0.001$ & 0.023 & $<0.001$ & 0.021 \\
\hline \multirow[t]{2}{*}{ Medial 50\% } & Human male & $<0.001$ & $<0.001$ & $<0.001$ & $<0.001$ & 0.031 \\
\hline & Human female & $<0.001$ & $<0.001$ & $<0.001$ & $<0.001$ & $<0.001$ \\
\hline \multirow[t]{2}{*}{ Lateral $50 \%$} & Human male & $<0.001$ & $<0.001$ & $<0.001$ & $<0.001$ & 0.001 \\
\hline & Human female & $<0.001$ & $<0.001$ & 0.002 & $<0.001$ & $<0.001$ \\
\hline \multirow[t]{2}{*}{ Anterior $50 \%$} & Human male & $<0.001$ & $<0.001$ & 0.149 & $<0.001$ & $<0.001$ \\
\hline & Human female & 0.720 & 0.004 & 0.009 & $<0.001$ & $<0.001$ \\
\hline \multirow[t]{2}{*}{ Posterior 50\% } & Human male & $<0.001$ & $<0.001$ & $<0.001$ & $<0.001$ & 0.927 \\
\hline & Human female & $<0.001$ & $<0.001$ & $<0.001$ & $<0.001$ & 0.998 \\
\hline \multirow[t]{2}{*}{ Medial 60\% } & Human male & $<0.001$ & $<0.001$ & $<0.001$ & $<0.001$ & 0.012 \\
\hline & Human female & $<0.001$ & $<0.001$ & $<0.001$ & $<0.001$ & $<0.001$ \\
\hline \multirow[t]{2}{*}{ Lateral $60 \%$} & Human male & $<0.001$ & $<0.001$ & 0.810 & $<0.001$ & $<0.001$ \\
\hline & Human female & $<0.001$ & $<0.001$ & 0.005 & $<0.001$ & $<0.001$ \\
\hline \multirow[t]{2}{*}{ Anterior $60 \%$} & Human male & 0.041 & 0.678 & $<0.001$ & $<0.001$ & $<0.001$ \\
\hline & Human female & 0.147 & $<0.001$ & 0.199 & $<0.001$ & $<0.001$ \\
\hline \multirow[t]{2}{*}{ Posterior $60 \%$} & Human male & $<0.001$ & $<0.001$ & $<0.001$ & $<0.001$ & 0.025 \\
\hline & Human female & $<0.001$ & $<0.001$ & $<0.001$ & $<0.001$ & 0.018 \\
\hline \multirow[t]{2}{*}{ Medial $70 \%$} & Human male & $<0.001$ & $<0.001$ & $<0.001$ & $<0.001$ & $<0.001$ \\
\hline & Human female & 0.056 & 0.002 & 0.069 & $<0.001$ & $<0.001$ \\
\hline \multirow[t]{2}{*}{ Lateral $70 \%$} & Human male & $<0.001$ & $<0.001$ & 0.003 & $<0.001$ & $<0.001$ \\
\hline & Human female & 0.597 & 0.226 & 0.396 & $<0.001$ & $<0.001$ \\
\hline \multirow[t]{2}{*}{ Anterior $70 \%$} & Human male & 0.094 & $<0.001$ & $<0.001$ & $<0.001$ & 0.635 \\
\hline & Human female & 0.017 & 0.821 & 0.036 & 0.022 & 0.010 \\
\hline \multirow[t]{2}{*}{ Posterior $70 \%$} & Human male & $<0.001$ & $<0.001$ & $<0.001$ & $<0.001$ & $<0.001$ \\
\hline & Human female & $<0.001$ & $<0.001$ & $<0.001$ & $<0.001$ & $<0.001$ \\
\hline
\end{tabular}

Table 9. Femur cortical bone thickness: $p$ values from t-tests; values below 0.05 indicate significant difference. Bold type $=$ human group is significantly greater than non-human group; italic type $=$ human group is significantly less than non-human group.

Cortical bone thickness - tibia

The large figures for anterior cortical bone thickness in the human (Table 10) reflect the prominent anterior border (and the standard deviation also reflects variation in the thickness of the underlying bone). The proximal end of the kangaroo tibia is dominated by an extremely prominent, but thin, 
anterior border and a considerable lateral border, so although the measurements for cortical bone thickness include these ridges, they should be disregarded for comparative purposes as they are not functionally equivalent to thick cortical bone elsewhere. The distinction between cortical and cancellous bone was too difficult to determine at the $30 \%$ length level in the cattle and juvenile pig tibiae.

\begin{tabular}{|c|c|c|c|c|c|c|c|c|c|c|}
\hline \multicolumn{3}{|c|}{ Length } & \multicolumn{2}{|c|}{ Medial } & \multicolumn{2}{|c|}{ Lateral } & \multicolumn{2}{|c|}{ Anterior } & \multicolumn{2}{|c|}{ Posterior } \\
\hline level & Group & $n$ & Mean & SD & Mean & $\mathrm{SD}$ & Mean & $\mathrm{SD}$ & Mean & $\mathrm{SD}$ \\
\hline \multirow[t]{7}{*}{$30 \%$} & Kangaroo & 24 & 4.02 & 0.54 & 10.41 & 2.54 & 6.72 & 1.55 & 5.17 & 1.14 \\
\hline & Sheep & 24 & 2.83 & 0.40 & 3.67 & 0.46 & 3.71 & 0.75 & 3.23 & 0.50 \\
\hline & Pig (juvenile) & 23 & 2.74 & 0.56 & 3.35 & 0.69 & - & - & 2.36 & 0.68 \\
\hline & Dog (greyhound) & 18 & 2.63 & 0.29 & 3.78 & 0.55 & 4.89 & 0.87 & 3.88 & 0.66 \\
\hline & Cattle & 24 & 5.36 & 0.72 & 9.19 & 1.83 & - & - & 5.85 & 1.93 \\
\hline & Human male & 25 & 3.45 & 0.57 & 3.63 & 0.95 & 6.85 & 1.92 & 4.28 & 1.27 \\
\hline & Human female & 25 & 2.68 & 0.94 & 3.03 & 1.08 & 4.71 & 1.83 & 3.84 & 1.30 \\
\hline \multirow[t]{7}{*}{$40 \%$} & Kangaroo & 24 & 3.84 & 0.60 & 8.50 & 2.33 & $\mathbf{5 . 3 5}$ & 0.97 & 5.19 & 0.72 \\
\hline & Sheep & 24 & 3.29 & 0.43 & 3.58 & 0.51 & 3.44 & 0.49 & 3.40 & 0.54 \\
\hline & Pig (juvenile) & 23 & 3.61 & 0.72 & 4.25 & 0.84 & 5.17 & 1.71 & 3.16 & 0.66 \\
\hline & Dog (greyhound) & 18 & 2.59 & 0.28 & 4.26 & 0.68 & 4.02 & 0.47 & 4.06 & 0.50 \\
\hline & Cattle & 24 & 7.78 & 0.87 & 11.01 & 1.77 & 9.18 & 1.73 & 6.69 & 0.78 \\
\hline & Human male & 25 & 4.02 & 0.73 & 4.80 & 1.17 & 9.25 & 2.04 & 4.97 & 0.94 \\
\hline & Human female & 25 & 3.18 & 1.04 & 3.51 & 0.99 & 6.15 & 2.38 & 4.16 & 1.28 \\
\hline \multirow[t]{7}{*}{$50 \%$} & Kangaroo & 24 & 4.16 & 0.65 & 4.74 & 0.99 & 4.79 & 0.78 & 5.01 & 0.82 \\
\hline & Sheep & 24 & 3.53 & 0.51 & 3.51 & 0.46 & 3.25 & 0.55 & 3.39 & 0.45 \\
\hline & Pig (juvenile) & 23 & 5.08 & 0.98 & 5.30 & 1.27 & 5.20 & 0.85 & 3.62 & 0.48 \\
\hline & Dog (greyhound) & 18 & 2.91 & 0.31 & 3.42 & 0.48 & 3.69 & 0.49 & 4.39 & 0.52 \\
\hline & Cattle & 24 & 10.14 & 1.31 & 11.26 & 1.82 & 7.98 & 1.14 & 8.13 & 0.87 \\
\hline & Human male & 25 & 4.33 & 0.83 & 5.23 & 1.15 & 9.62 & 2.06 & 5.28 & 1.04 \\
\hline & Human female & 25 & 3.31 & 1.15 & 3.77 & 1.14 & 6.80 & 2.52 & 4.33 & 1.26 \\
\hline \multirow[t]{7}{*}{$60 \%$} & Kangaroo & 24 & 4.39 & 0.56 & 4.18 & 0.80 & 4.48 & 0.76 & 4.53 & 0.69 \\
\hline & Sheep & 24 & 3.63 & 0.49 & 3.63 & 0.35 & 3.18 & 0.37 & 3.27 & 0.45 \\
\hline & Pig (juvenile) & 23 & 5.50 & 1.05 & 4.74 & 0.88 & 3.77 & 0.66 & 3.39 & 0.41 \\
\hline & Dog (greyhound) & 18 & 3.10 & 0.33 & 2.97 & 0.37 & 3.47 & 0.50 & 4.18 & 0.48 \\
\hline & Cattle & 24 & 10.25 & 1.62 & 9.91 & 1.91 & 7.03 & 1.20 & 8.19 & 1.15 \\
\hline & Human male & 25 & 4.60 & 1.15 & 4.53 & 0.84 & 8.71 & 1.89 & 5.45 & 1.32 \\
\hline & Human female & 25 & 3.36 & 1.02 & 3.24 & 0.85 & 5.86 & 1.89 & 4.24 & 1.14 \\
\hline \multirow[t]{7}{*}{$70 \%$} & Kangaroo & 24 & 4.38 & 0.56 & 3.80 & 0.71 & 4.25 & 0.71 & 3.92 & 0.55 \\
\hline & Sheep & 24 & 3.63 & 0.41 & 3.50 & 0.34 & 3.19 & 0.34 & 3.06 & 0.31 \\
\hline & Pig (juvenile) & 23 & 4.52 & 0.88 & 3.46 & 0.86 & 2.87 & 0.50 & 2.67 & 0.46 \\
\hline & Dog (greyhound) & 18 & 2.95 & 0.34 & 2.76 & 0.24 & 3.14 & 0.35 & 3.33 & 0.35 \\
\hline & Cattle & 24 & 8.63 & 1.24 & 7.97 & 1.44 & 6.79 & 1.25 & 6.56 & 1.00 \\
\hline & Human male & 25 & 4.00 & 0.92 & 3.89 & 0.70 & 6.07 & 1.37 & 4.55 & 1.18 \\
\hline & Human female & 25 & 3.12 & 0.90 & 2.79 & 0.83 & $3.96^{\mathrm{a}}$ & 1.15 & $3.60^{\mathrm{a}}$ & 0.99 \\
\hline
\end{tabular}

Table 10. Tibia cortical bone thickness: mean and standard deviation (SD) for all length levels of all groups. Measurements in millimetres. ${ }^{a} n=24$ for that variable in that sample. 
The tibial cortical bone thickness in the human groups was significantly less than almost all the corresponding measurement sites in the cattle (Table 11). The comparison between humans and the other non-human groups varied across the measurement sites. Frequently, there would be a range in differences between the human and each non-human group from significantly greater to no significant difference to significantly less just at the same level on the shaft between the four different cortices being measured.

\begin{tabular}{|c|c|c|c|c|c|c|}
\hline $\begin{array}{l}\text { Cortical thickness } \\
\text { and length level }\end{array}$ & Human group & $\begin{array}{r}\text { Medium } \\
\text { kangaroo }\end{array}$ & Sheep & $\begin{array}{c}\text { Pig } \\
\text { juvenile }\end{array}$ & $\begin{array}{c}\text { Dog } \\
\text { greyhound }\end{array}$ & Cattle \\
\hline \multirow[t]{2}{*}{ Medial 30\% } & Human male & 0.001 & $<0.001$ & $<0.001$ & $<0.001$ & $<0.001$ \\
\hline & Human female & $<0.001$ & 0.474 & 0.790 & 0.828 & $<0.001$ \\
\hline \multirow[t]{2}{*}{ Lateral $30 \%$} & Human male & $<0.001$ & 0.854 & 0.252 & 0.530 & $<0.001$ \\
\hline & Human female & $<0.001$ & 0.010 & 0.232 & 0.009 & $<0.001$ \\
\hline \multirow[t]{2}{*}{ Anterior $30 \%$} & Human male & 0.798 & $<0.001$ & - & $<0.001$ & - \\
\hline & Human female & $<0.001$ & 0.017 & - & 0.693 & - \\
\hline \multirow[t]{2}{*}{ Posterior $30 \%$} & Human male & 0.013 & $<0.001$ & $<0.001$ & 0.232 & 0.001 \\
\hline & Human female & $<0.001$ & 0.039 & $<0.001$ & 0.887 & $<0.001$ \\
\hline \multirow[t]{2}{*}{ Medial $40 \%$} & Human male & 0.349 & $<0.001$ & 0.061 & $<0.001$ & $<0.001$ \\
\hline & Human female & 0.010 & 0.618 & 0.101 & 0.025 & $<0.001$ \\
\hline \multirow[t]{2}{*}{ Lateral $40 \%$} & Human male & $<0.001$ & $<0.001$ & 0.068 & 0.086 & $<0.001$ \\
\hline & Human female & $<0.001$ & 0.753 & 0.008 & 0.008 & $<0.001$ \\
\hline \multirow[t]{2}{*}{ Anterior $40 \%$} & Human male & $<0.001$ & $<0.001$ & $<0.001$ & $<0.001$ & 0.898 \\
\hline & Human female & 0.134 & $<0.001$ & 0.111 & $<0.001$ & $<0.001$ \\
\hline \multirow[t]{2}{*}{ Posterior $40 \%$} & Human male & 0.370 & $<0.001$ & $<0.001$ & $<0.001$ & $<0.001$ \\
\hline & Human female & 0.001 & 0.010 & 0.002 & 0.765 & $<0.001$ \\
\hline \multirow[t]{2}{*}{ Medial 50\% } & Human male & 0.442 & $<0.001$ & 0.006 & $<0.001$ & $<0.001$ \\
\hline & Human female & 0.003 & 0.385 & $<0.001$ & 0.155 & $<0.001$ \\
\hline \multirow[t]{2}{*}{ Lateral $50 \%$} & Human male & 0.116 & $<0.001$ & 0.856 & $<0.001$ & $<0.001$ \\
\hline & Human female & 0.002 & 0.299 & $<0.001$ & 0.235 & $<0.001$ \\
\hline \multirow[t]{2}{*}{ Anterior 50\% } & Human male & $<0.001$ & $<0.001$ & $<0.001$ & $<0.001$ & 0.001 \\
\hline & Human female & 0.001 & $<0.001$ & 0.006 & $<0.001$ & 0.042 \\
\hline \multirow[t]{2}{*}{ Posterior 50\% } & Human male & 0.331 & $<0.001$ & $<0.001$ & 0.002 & $<0.001$ \\
\hline & Human female & 0.030 & 0.001 & 0.014 & 0.848 & $<0.001$ \\
\hline \multirow[t]{2}{*}{ Medial 60\% } & Human male & 0.406 & $<0.001$ & 0.008 & $<0.001$ & $<0.001$ \\
\hline & Human female & $<0.001$ & 0.251 & $<0.001$ & 0.298 & $<0.001$ \\
\hline \multirow[t]{2}{*}{ Lateral $60 \%$} & Human male & 0.139 & $<0.001$ & 0.389 & $<0.001$ & $<0.001$ \\
\hline & Human female & $<0.001$ & 0.042 & $<0.001$ & 0.213 & $<0.001$ \\
\hline \multirow[t]{2}{*}{ Anterior $60 \%$} & Human male & $<0.001$ & $<0.001$ & $<0.001$ & $<0.001$ & 0.001 \\
\hline & Human female & 0.002 & $<0.001$ & $<0.001$ & $<0.001$ & 0.013 \\
\hline \multirow[t]{2}{*}{ Posterior $60 \%$} & Human male & 0.004 & $<0.001$ & $<0.001$ & $<0.001$ & $<0.001$ \\
\hline & Human female & 0.295 & $<0.001$ & 0.001 & 0.823 & $<0.001$ \\
\hline \multirow[t]{2}{*}{ Medial 70\% } & Human male & 0.087 & 0.081 & 0.052 & $<0.001$ & $<0.001$ \\
\hline & Human female & $<0.001$ & 0.014 & $<0.001$ & 0.448 & $<0.001$ \\
\hline \multirow[t]{2}{*}{ Lateral $70 \%$} & Human male & 0.646 & 0.016 & 0.061 & $<0.001$ & $<0.001$ \\
\hline & Human female & $<0.001$ & $<0.001$ & 0.009 & 0.881 & $<0.001$ \\
\hline \multirow[t]{2}{*}{ Anterior $70 \%$} & Human male & $<0.001$ & $<0.001$ & $<0.001$ & $<0.001$ & 0.060 \\
\hline & Human female & 0.302 & 0.003 & $<0.001$ & 0.006 & $<0.001$ \\
\hline \multirow[t]{2}{*}{ Posterior 70\% } & Human male & 0.021 & $<0.001$ & $<0.001$ & $<0.001$ & $<0.001$ \\
\hline & Human female & 0.173 & 0.015 & $<0.001$ & 0.295 & $<0.001$ \\
\hline
\end{tabular}

Table 11. Tibia cortical bone thickness: $p$ values from t-tests; values below 0.05 indicate significant difference. Bold type = human group is significantly greater than non-human group; italic type = human group is significantly less than non-human group. 


\section{Cortical thickness index}

The total human sample was again split by sex for consistency for this analysis, although generally there were very few significant differences between the male and female groups in cortical thickness index. The only variables showing significant differences were: for the humerus, both indices at the $70 \%$ level; for the femur, mediolateral index at the $50 \%$ and $70 \%$ level; for the tibia, both indices at all but the $30 \%$ length level.

For the humerus, the mean indices for the human groups range from 0.283 to 0.434 , overlapping with many of the non-human group means (Figure 4). The results of t-tests comparing the variables in turn between both the human groups and each of the non-human groups is shown in Table 12 (again, there were too few kangaroo humeri for statistical comparison). There is no clear pattern of difference between the human and non-human groups in the cortical thickness index of the humerus; non-human variables can be either significantly greater than, significantly less than, or of no significant difference to the corresponding human group. The human groups had generally greater cortical thickness indices in the proximal humerus due to the relatively expanded shaft in this area in the non-human groups, which reduced their overall cortical thickness index.

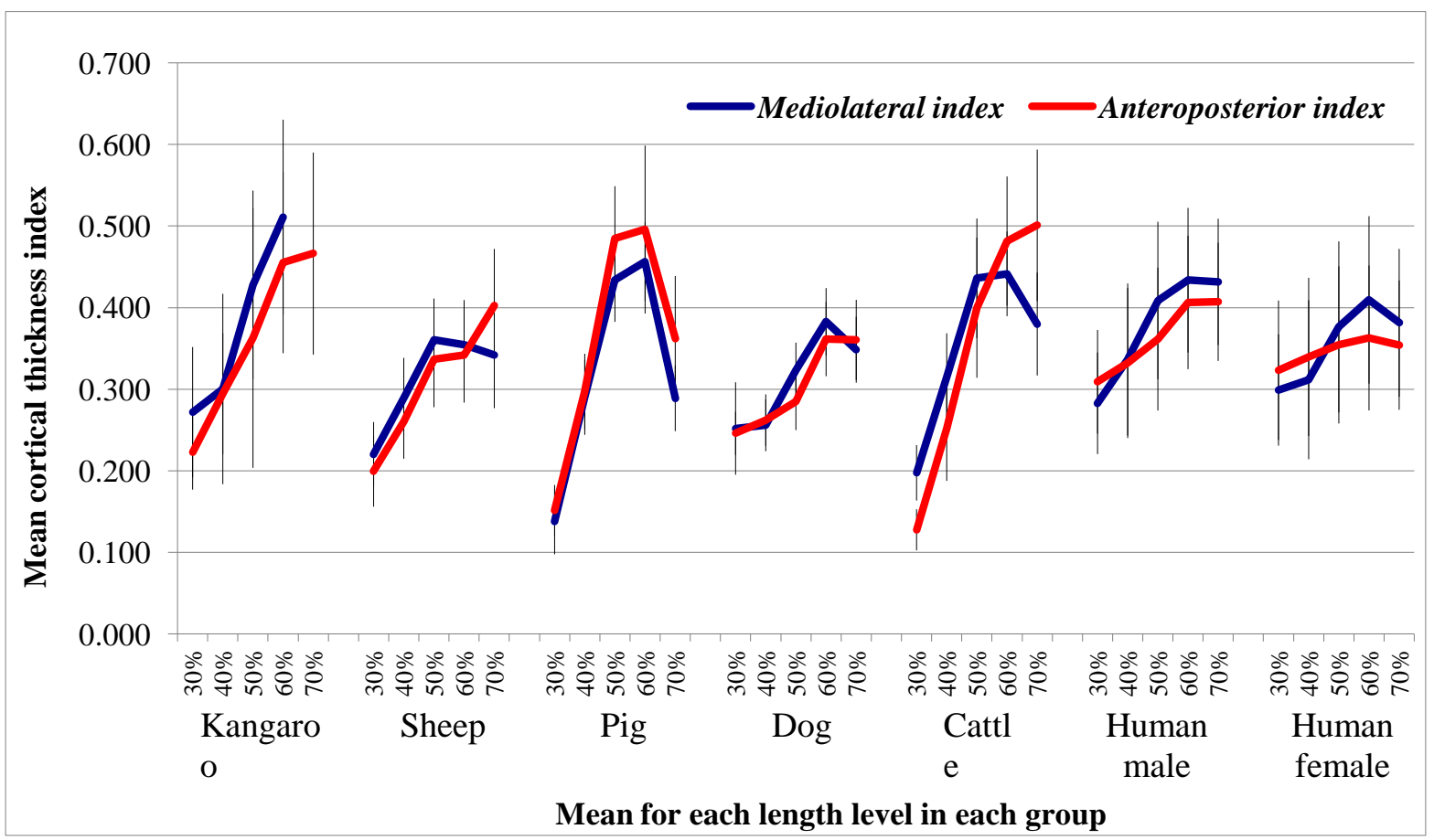

Figure 4. Mean cortical thickness index for humerus for each length level in each group. Error bars are one standard deviation. $\mathrm{Pig}=$ juvenile pig; $\mathrm{Dog}=$ greyhound. 


\begin{tabular}{llrrrr}
\hline $\begin{array}{l}\text { Cortical thickness index } \\
\text { and length level }\end{array}$ & Human group & Sheep & $\begin{array}{c}\text { Pig } \\
\text { juvenile }\end{array}$ & $\begin{array}{r}\text { Dog } \\
\text { greyhound }\end{array}$ & Cattle \\
\hline Mediolateral 30\% & Human male & $<\mathbf{0 . 0 0 1}$ & $<\mathbf{0 . 0 0 1}$ & 0.098 & $<\mathbf{0 . 0 0 1}$ \\
& Human female & $<\mathbf{0 . 0 0 1}$ & $<\mathbf{0 . 0 0 1}$ & $\mathbf{0 . 0 1 9}$ & $<\mathbf{0 . 0 0 1}$ \\
Anteroposterior 30\% & Human male & $<\mathbf{0 . 0 0 1}$ & $<\mathbf{0 . 0 0 1}$ & $<\mathbf{0 . 0 0 1}$ & $<\mathbf{0 . 0 0 1}$ \\
& Human female & $<\mathbf{0 . 0 0 1}$ & $<\mathbf{0 . 0 0 1}$ & $<\mathbf{0 . 0 0 1}$ & $<\mathbf{0 . 0 0 1}$ \\
\hline Mediolateral 40\% & Human male & $\mathbf{0 . 0 3 3}$ & 0.059 & $<\mathbf{0 . 0 0 1}$ & 0.304 \\
& Human female & 0.323 & 0.388 & $\mathbf{0 . 0 2 1}$ & 0.861 \\
Anteroposterior 40\% & Human male & $\mathbf{0 . 0 0 1}$ & 0.145 & $\mathbf{0 . 0 0 3}$ & $<\mathbf{0 . 0 0 1}$ \\
& Human female & $\mathbf{0 . 0 0 1}$ & 0.093 & $\mathbf{0 . 0 0 2}$ & $<\mathbf{0 . 0 0 1}$ \\
\hline Mediolateral 50\% & Human male & $\mathbf{0 . 0 3 4}$ & 0.322 & $<\mathbf{0 . 0 0 1}$ & 0.246 \\
& Human female & 0.500 & 0.038 & $\mathbf{0 . 0 3 9}$ & 0.018 \\
Anteroposterior 50\% & Human male & 0.251 & $<0.001$ & $<\mathbf{0 . 0 0 1}$ & 0.110 \\
& Human female & 0.444 & $<0.001$ & $\mathbf{0 . 0 0 5}$ & 0.071 \\
\hline Mediolateral 60\% & Human male & $<\mathbf{0 . 0 0 1}$ & 0.329 & $\mathbf{0 . 0 2 6}$ & 0.689 \\
& Human female & $\mathbf{0 . 0 2 4}$ & 0.080 & 0.291 & 0.146 \\
Anteroposterior 60\% & Human male & $\mathbf{0 . 0 0 3}$ & 0.003 & $\mathbf{0 . 0 3 8}$ & 0.001 \\
& Human female & 0.330 & $<0.001$ & 0.955 & $<0.001$ \\
\hline Mediolateral 70\% & Human male & $<\mathbf{0 . 0 0 1}$ & $<\mathbf{0 . 0 0 1}$ & $<\mathbf{0 . 0 0 1}$ & $\mathbf{0 . 0 0 9}$ \\
& Human female & 0.088 & $<\mathbf{0 . 0 0 1}$ & 0.147 & 0.941 \\
Anteroposterior 70\% & Human male & 0.826 & $<\mathbf{0 . 0 0 1}$ & $\mathbf{0 . 0 2 0}$ & $<0.001$ \\
& Human female & 0.028 & 0.753 & 0.764 & $<0.001$ \\
\hline
\end{tabular}

Table 12. Humerus cortical thickness index: $p$ values from t-tests; values below 0.05 indicate

significant difference. Bold type = human group is significantly greater than non-human group; italic type $=$ human group is significantly less than non-human group.

Figure 5 shows the mean cortical thickness index for all measurement sites of the radius, and Table 13 shows the results from the t-tests comparing the human and non-human groups. Pig radial cortical thickness index was not calculated due to too many missing data points. The human radii showed a different pattern of relative thickness down the shaft than the non-human taxa, being greatest towards the middle of the shaft in both orientations. At the most proximal measurement site, the human cortical thickness index was generally significantly less than each of the non-human groups. For other sites, there was either no difference or, increasingly towards the distal end, the human cortical thickness index was significantly greater than in several of the non-human groups. This is partly accounted for by the increase in shaft diameter distally in those non-human groups. 


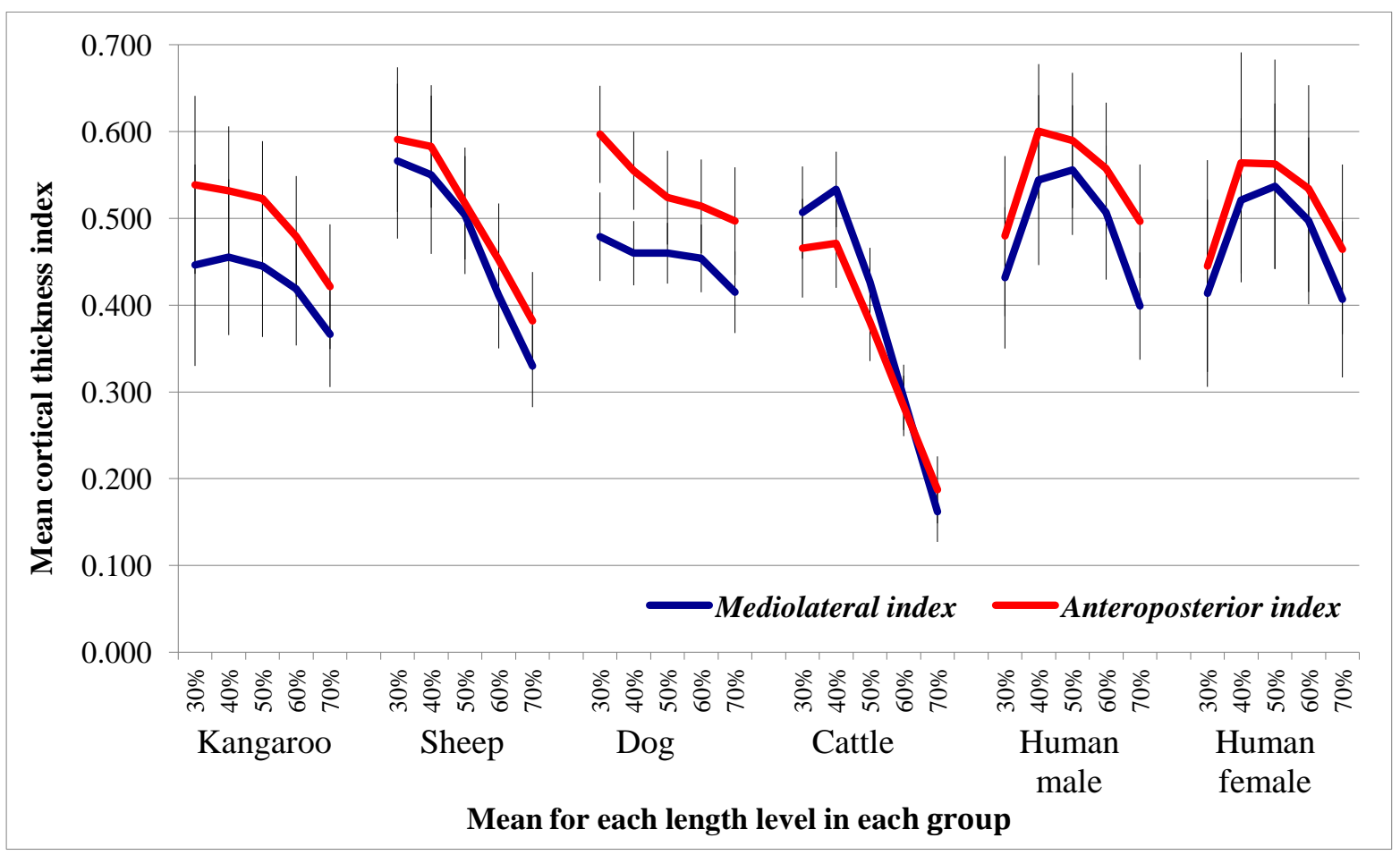

Figure 5. Mean cortical thickness index for radius for each length level in each group. Error bars are one standard deviation. Dog = greyhound.

\begin{tabular}{llrrrr}
\hline $\begin{array}{l}\text { Cortical thickness index } \\
\text { and length level }\end{array}$ & Human group & $\begin{array}{r}\text { Medium } \\
\text { kangaroo }\end{array}$ & Sheep & $\begin{array}{r}\text { Dog } \\
\text { greyhound }\end{array}$ & Cattle \\
\hline Mediolateral 30\% & Human male & 0.612 & $<0.001$ & 0.023 & $<0.001$ \\
& Human female & 0.317 & $<0.001$ & 0.013 & $<0.001$ \\
Anteroposterior 30\% & Human male & 0.039 & $<0.001$ & $<0.001$ & 0.506 \\
& Human female & 0.006 & $<0.001$ & $<0.001$ & 0.428 \\
\hline Mediolateral 40\% & Human male & $\mathbf{0 . 0 0 2}$ & 0.816 & $<\mathbf{0 . 0 0 1}$ & 0.600 \\
& Human female & $\mathbf{0 . 0 1 6}$ & 0.259 & $\mathbf{0 . 0 0 7}$ & 0.532 \\
Anteroposterior 40\% & Human male & $\mathbf{0 . 0 0 3}$ & 0.403 & $\mathbf{0 . 0 2 0}$ & $<\mathbf{0 . 0 0 1}$ \\
& Human female & 0.286 & 0.506 & 0.751 & $\mathbf{0 . 0 0 1}$ \\
\hline Mediolateral 50\% & Human male & $<\mathbf{0 . 0 0 1}$ & $\mathbf{0 . 0 1 2}$ & $<\mathbf{0 . 0 0 1}$ & $<\mathbf{0 . 0 0 1}$ \\
& Human female & $\mathbf{0 . 0 0 1}$ & 0.153 & $<\mathbf{0 . 0 0 1}$ & $<\mathbf{0 . 0 0 1}$ \\
Anteroposterior 50\% & Human male & $\mathbf{0 . 0 0 2}$ & $\mathbf{0 . 0 0 1}$ & $\mathbf{0 . 0 0 2}$ & $<\mathbf{0 . 0 0 1}$ \\
& Human female & 0.158 & 0.093 & 0.176 & $<\mathbf{0 . 0 0 1}$ \\
\hline Mediolateral 60\% & Human male & $<\mathbf{0 . 0 0 1}$ & $<\mathbf{0 . 0 0 1}$ & $\mathbf{0 . 0 0 6}$ & $<\mathbf{0 . 0 0 1}$ \\
& Human female & $\mathbf{0 . 0 0 2}$ & $<\mathbf{0 . 0 0 1}$ & 0.058 & $<\mathbf{0 . 0 0 1}$ \\
Anteroposterior 60\% & Human male & $<\mathbf{0 . 0 0 1}$ & $<\mathbf{0 . 0 0 1}$ & $\mathbf{0 . 0 3 0}$ & $<\mathbf{0 . 0 0 1}$ \\
& Human female & 0.055 & $\mathbf{0 . 0 0 3}$ & 0.455 & $<\mathbf{0 . 0 0 1}$ \\
\hline Mediolateral 70\% & Human male & 0.070 & $<\mathbf{0 . 0 0 1}$ & 0.336 & $<\mathbf{0 . 0 0 1}$ \\
& Human female & 0.074 & $<\mathbf{0 . 0 0 1}$ & 0.709 & $<\mathbf{0 . 0 0 1}$ \\
Anteroposterior 70\% & Human male & $<\mathbf{0 . 0 0 1}$ & $<\mathbf{0 . 0 0 1}$ & 0.973 & $<\mathbf{0 . 0 0 1}$ \\
& Human female & 0.087 & $<\mathbf{0 . 0 0 1}$ & 0.181 & $<\mathbf{0 . 0 0 1}$ \\
\hline
\end{tabular}

Table 13. Radius cortical thickness index: $p$ values from t-tests; values below 0.05 indicate significant difference. Bold type $=$ human group is significantly greater than non-human group; italic type $=$ human group is significantly less than non-human group.

The thick cortices of the human femora were reflected in the cortical thickness indices (Figure 6), with the mean cortical thickness index greatest in the human groups except at the distal end of the 
shaft. As a result, Table 14 shows that human cortical thickness indices were statistically greater than their corresponding non-human indices for almost all measurement sites barring the $70 \%$ length level (where some of the human indices were actually significantly less than some non-human indices). Several of the mean indices for the human femur were greater than 0.500 , whereas the highest nonhuman mean was 0.435 .

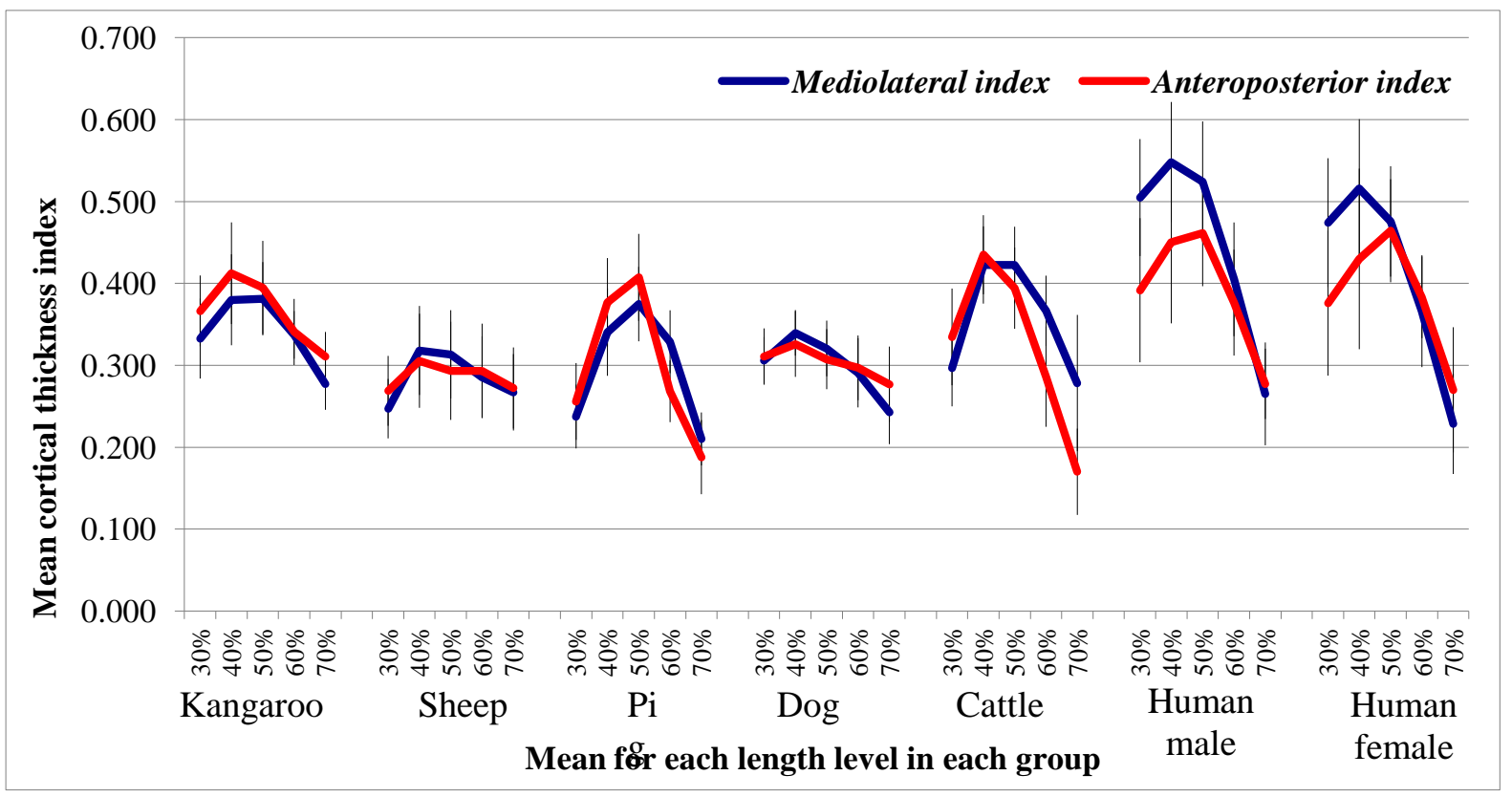

Figure 6. Mean cortical thickness index for femur for each length level in each group. Error bars are one standard deviation. Pig = juvenile pig; Dog = greyhound.

\begin{tabular}{|c|c|c|c|c|c|c|}
\hline $\begin{array}{l}\text { Cortical thickness } \\
\text { index and length level }\end{array}$ & Human group & $\begin{array}{r}\text { Medium } \\
\text { kangaroo }\end{array}$ & Sheep & $\begin{array}{l}\text { Pig } \\
\text { juvenile }\end{array}$ & $\begin{array}{c}\text { Dog } \\
\text { greyhound }\end{array}$ & Cattle \\
\hline \multirow{2}{*}{ Mediolateral 30\% } & Human male & $<0.001$ & $<0.001$ & $<0.001$ & $<0.001$ & $<0.001$ \\
\hline & Human female & $<0.001$ & $<0.001$ & $<0.001$ & $<0.001$ & $<0.001$ \\
\hline \multirow{2}{*}{ Anteroposterior $30 \%$} & Human male & 0.179 & $<0.001$ & $<0.001$ & $<0.001$ & 0.011 \\
\hline & Human female & 0.614 & $<0.001$ & $<0.001$ & 0.002 & 0.066 \\
\hline \multirow[t]{2}{*}{ Mediolateral $40 \%$} & Human male & $<0.001$ & $<0.001$ & $<0.001$ & $<0.001$ & $<0.001$ \\
\hline & Human female & $<0.001$ & $<0.001$ & $<0.001$ & $<0.001$ & $<0.001$ \\
\hline \multirow[t]{2}{*}{ Anteroposterior $40 \%$} & Human male & 0.093 & $<0.001$ & 0.002 & $<0.001$ & 0.494 \\
\hline & Human female & 0.474 & $<0.001$ & 0.032 & $<0.001$ & 0.836 \\
\hline \multirow[t]{2}{*}{ Mediolateral 50\% } & Human male & $<0.001$ & $<0.001$ & $<0.001$ & $<0.001$ & $<0.001$ \\
\hline & Human female & $<0.001$ & $<0.001$ & $<0.001$ & $<0.001$ & 0.002 \\
\hline \multirow[t]{2}{*}{ Anteroposterior $50 \%$} & Human male & $<0.001$ & $<0.001$ & 0.002 & $<0.001$ & $<0.001$ \\
\hline & Human female & $<0.001$ & $<0.001$ & 0.001 & $<0.001$ & $<0.001$ \\
\hline \multirow[t]{2}{*}{ Mediolateral $60 \%$} & Human male & $<0.001$ & $<0.001$ & $<0.001$ & $<0.001$ & 0.025 \\
\hline & Human female & 0.043 & $<0.001$ & 0.018 & $<0.001$ & 0.979 \\
\hline \multirow[t]{2}{*}{ Anteroposterior $60 \%$} & Human male & 0.016 & $<0.001$ & $<0.001$ & $<0.001$ & $<0.001$ \\
\hline & Human female & 0.001 & $<0.001$ & $<0.001$ & $<0.001$ & $<0.001$ \\
\hline \multirow[t]{2}{*}{ Mediolateral 70\% } & Human male & 0.363 & 0.897 & $<0.001$ & 0.041 & 0.532 \\
\hline & Human female & $<0.001$ & 0.012 & 0.177 & 0.886 & 0.020 \\
\hline \multirow[t]{2}{*}{ Anteroposterior $70 \%$} & Human male & 0.001 & 0.694 & $<0.001$ & 0.319 & $<0.001$ \\
\hline & Human female & 0.011 & 0.898 & $<0.001$ & 0.766 & $<0.001$ \\
\hline
\end{tabular}

Table 14. Femur cortical thickness index: $p$ values from t-tests; values below 0.05 indicate significant difference. Bold type $=$ human group is significantly greater than non-human group; italic type $=$ human group is significantly less than non-human group. 
The mean cortical thickness indices for the tibia (Figure 7) were similar between the human and the non-human groups as a whole, particularly around the midshaft. The female human group showed considerable variability within the sample, reflected in a higher standard deviation than other groups. Few measurement sites in the human groups were significantly greater than corresponding sites in the non-human groups (Table 15). Many measurement sites showed no significant difference between human and non-human groups, but all non-human groups had at least a few sites where the human groups (usually the female group) were significantly less than the non-human group.

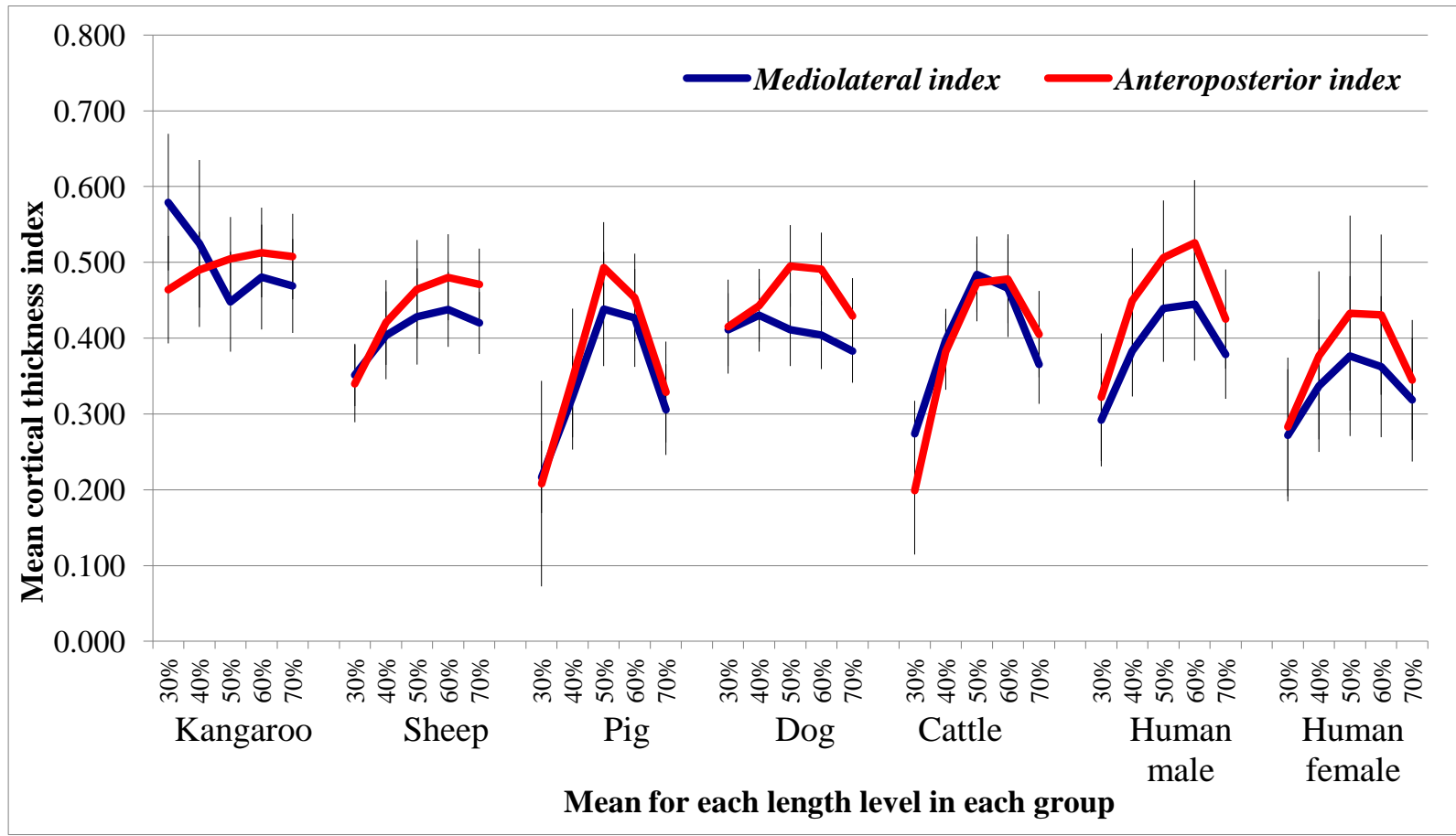

Figure 7. Mean cortical thickness index for tibia for each length level in each group. Error bars are one standard deviation. Pig = juvenile pig; Dog = greyhound. 


\begin{tabular}{llccccc}
\hline $\begin{array}{l}\text { Cortical thickness } \\
\text { index and length level }\end{array}$ & Human group & $\begin{array}{c}\text { Medium } \\
\text { kangaroo }\end{array}$ & Sheep & $\begin{array}{c}\text { Pig } \\
\text { juvenile }\end{array}$ & $\begin{array}{c}\text { Dog } \\
\text { greyhound }\end{array}$ & Cattle \\
\hline Mediolateral 30\% & Human male & $<0.001$ & $<0.001$ & $<\mathbf{0 . 0 0 1}$ & $<0.001$ & 0.239 \\
& Human female & $<0.001$ & $<0.001$ & $\mathbf{0 . 0 1 0}$ & $<0.001$ & 0.909 \\
Anteroposterior 30\% & Human male & $<0.001$ & 0.373 & - & $<0.001$ & - \\
& Human female & $<0.001$ & 0.010 & - & $<0.001$ & - \\
\hline Mediolateral 40\% & Human male & $<0.001$ & 0.231 & $\mathbf{0 . 0 0 1}$ & 0.009 & 0.342 \\
& Human female & $<0.001$ & 0.003 & 0.499 & $<0.001$ & 0.004 \\
Anteroposterior 40\% & Human male & 0.024 & 0.118 & $<\mathbf{0 . 0 0 1}$ & 0.746 & $<\mathbf{0 . 0 0 1}$ \\
& Human female & $<0.001$ & 0.092 & 0.297 & 0.023 & 0.851 \\
\hline Mediolateral 50\% & Human male & 0.665 & 0.575 & 0.963 & 0.156 & 0.014 \\
& Human female & 0.008 & 0.042 & 0.024 & 0.194 & $<0.001$ \\
Anteroposterior 50\% & Human male & 0.934 & $\mathbf{0 . 0 4 5}$ & 0.512 & 0.589 & 0.080 \\
& Human female & 0.018 & 0.286 & 0.047 & 0.062 & 0.161 \\
\hline Mediolateral 60\% & Human male & 0.092 & 0.709 & 0.373 & $\mathbf{0 . 0 4 6}$ & 0.287 \\
& Human female & $<0.001$ & 0.001 & 0.008 & 0.086 & $<0.001$ \\
Anteroposterior 60\% & Human male & 0.535 & $\mathbf{0 . 0 2 9}$ & $\mathbf{0 . 0 0 1}$ & 0.119 & $\mathbf{0 . 0 2 4}$ \\
& Human female & 0.002 & 0.049 & 0.368 & 0.029 & 0.060 \\
\hline Mediolateral 70\% & Human male & $<0.001$ & 0.006 & $<\mathbf{0 . 0 0 1}$ & 0.788 & 0.410 \\
& Human female & $<0.001$ & $<0.001$ & 0.542 & 0.004 & 0.021 \\
Anteroposterior 70\% & Human male & $<0.001$ & 0.007 & $<\mathbf{0 . 0 0 1}$ & 0.835 & 0.263 \\
& Human female & $<0.001$ & $<0.001$ & 0.460 & $<0.001$ & 0.004 \\
\hline
\end{tabular}

Table 15. Tibia cortical thickness index: $p$ values from t-tests; values below 0.05 indicate significant difference. Bold type $=$ human group is significantly greater than non-human group; italic type $=$ human group is significantly less than non-human group.

As with the measurements of actual cortical bone thickness, there was no clear overall difference between human and non-human cortical thickness index. Results varied between the skeletal elements, the femur showing the clearest distinction with a generally significantly higher index for humans than the non-human groups. On the other hand, there was statistically no difference for some non-human groups and skeletal elements, and even for those that did show a difference, this was not consistently in one direction. Human cortical thickness index could be both greater and less than a single non-human group at the two different orientations, even at the same level of the shaft.

\section{Discussion}

Very little published research exists regarding simple methods, which can potentially be used in the field, for the identification of long bone shaft fragments. It was important to investigate the suggestion that differences in the thickness of the long bone cortical thickness could be compared for identification, as this would represent a straightforward identification tool if successful. This study did indeed find significant differences in both the actual and relative cortical bone thickness of humans and several non-human mammals, for several different skeletal elements. However, not all non-human taxa or skeletal elements showed differences when compared with human, and those that did were not always uniformly greater or less than the corresponding human measurement site. 
Brothwell's [13] comment that the cortical bone thickness varies between different mammals is therefore reflected well here, but it was a general statement. For the more defined viewpoints of other researchers, the results of this study offer less support. Ubelaker [14] stated that the cortical bone in animals similar in size to humans was thicker than human cortical bone, but without further details it is hard to make an accurate comparison. The current study certainly found that cattle bones were thicker (in terms of actual cortical bone thickness, not always in terms of relative cortical bone thickness), but these animals are much larger in body size than humans. Sheep, juvenile pigs and kangaroos are more similar in body size to humans. However, except for some parts of the pig humerus and tibia, sheep radius and kangaroo humerus, the actual cortical thickness in the human bones was generally similar to, or actually significantly greater than, the corresponding values in the other non-human groups.

Wolf [15] provides actual figures of relative cortical bone thickness for comparison. Perhaps Ubelaker's [14] statement was also based upon relative (rather than actual) cortical bone thickness. However, the results here showed no clearer evidence to support the comment that non-human bone is relatively thicker than human bone. Again, the relative thickness of the human bones being significantly greater, significantly less, or no different to the non-human bones varied not just with the skeletal element, but also the part of the shaft under comparison. Occasionally, even within the one length level, comparing humans with just one of the non-human groups, there were variations in the direction of the significant differences (human greater than non-human in one variable, less than nonhuman in another) depending on the sex of the human group and the orientation (anteroposterior or mediolateral) of the cortical thickness index. Therefore a general conclusion regarding whether human or non-human mammal bone have the thicker cortices is not possible based on these results.

The femur showed the most consistent results, with significant differences in relative cortical thickness between the humans and each of the non-human groups at most measurement sites. However, it was actually the human groups that had significantly greater relative cortical bone thickness than the non-human groups. This supports the previous work of Croker et al. [16] and Foote [16], both studies finding that relative cortical bone thickness is greatest in humans. These claims, however, are based on only one skeletal element (the femur), which in the non-human groups tested here happens to be generally lower in relative cortical bone thickness than in the other skeletal elements. It is therefore necessary to consider multiple skeletal elements when drawing conclusions about comparative cortical bone thickness. Wolf [15], though, did use the femur as an example, along with the humerus, when stating that non-human bones had relatively thicker cortices. He states that human cortical thickness is one-quarter of the total bone diameter, and in large mammals including cattle and sheep, it is one-third the total bone diameter (presumably this means the cortex on just one side, so should be doubled to compare with the results found here, that take into account the cortex on 
both sides of a cross-section). Wolf's [15] figure for the human femur fits quite well with the results obtained at the midshaft in this study (means of human subgroups 0.524, 0.476, 0.462, 0.464), although is a little high for the human humerus (means of human subgroups at midshaft 0.409, 0.376, $0.362,0.354)$. However, none of the non-human groups reached cortical thickness indices near the two-thirds indicated by Wolf [15], especially for the femoral and humeral shafts, the highest means being 0.435 for the femur (cattle anteroposterior cortical thickness index at $40 \%$ length level) and 0.485 for the humerus (pig anteroposterior at $50 \%$ length level. The kangaroo mediolateral $60 \%$ length level actually had the highest humeral measurement with a mean of 0.511 , but kangaroo was presumably not considered by Wolf [15].

Comparing the figures for relative cortical thickness with other human studies shows the results here to be similar, but generally a little lower. The modern Australian sample used in an earlier study [16] gave a mean femoral midshaft cortical thickness index of 0.515 (sides and sexes combined). A much earlier sample of Romano-British femora was studied by Kennedy [34], which gave cortical thickness index means from 0.4972 (female anteroposterior) to 0.5766 (male mediolateral). A limitation of the sample used for the current study is that the Terry collection is comprised of individuals generally of low socio-economic background, who died mostly in the early $20^{\text {th }}$ century. Poorer health and nutrition can lead to reduced cortical bone [22], which may account for the lower figures for the human groups found here in comparison to other human studies, but given the number of potential factors influencing cortical bone thickness, the results found here can be presumed to be comparable to previous works. Other limitations to be considered relate to the age ranges of the samples used, which varied considerably for the non-human groups, from juvenile for the pigs, to almost entirely adult for the dogs and kangaroos, and a mixture of juvenile and adult bones for the cattle and sheep. Although the samples used here are generally forensically relevant, it would be beneficial to know much more about the age profile of each sample, because cortical bone thickness has been found to vary with age in humans [21-22], and presumably does so for non-human mammals as well. Similarly, sex differences may be present in the non-human sample, but the sex of almost all the non-human specimens was not known. Although samples were gathered from numerous sources to try to avoid particular bias, future research needs to be undertaken on samples of known sex and document any sex-related differences. The dog sample used here reflects only one type of canine body morphology: that of a tall, gracile dog the size of a greyhound. Modern dogs, and their skeletons, vary enormously in size and shape between breeds; therefore, the greyhound-type sample used here should not be extrapolated to identify any other type of dog. Furthermore, relevant subgroups such as juvenile humans, mature pigs, and very large kangaroos have not been tested at all in this study; the results from these subgroups are likely, to some extent, to provide different results. Finally, the imaging method itself could be improved by using the same imaging system for both human and non-human 
bones (not logistically possible in this study), in order to reduce potential variables contributing to comparisons between human and non-human samples.

By considering a number of skeletal elements, and five common non-human mammals, this study has shown that the thickness of the cortical bone cannot be said to be thicker overall in either humans or non-human mammals. Although statistically significant differences existed at many of the measurement sites between humans and each of the non-human groups studied, it was the human bone that was significantly thicker in some cases, and the non-human bone that was significantly thicker in other cases. This applied to measurements of both actual and relative cortical bone thickness (although for cattle, almost every measurement site was significantly greater than the corresponding site in the human groups). With such differences existing even when comparing known, equivalent measurement sites, it would not be possible to positively identify an isolated fragment of a long bone using cortical thickness measurements alone. If the fragment is so small and undistinguished that there are no morphological clues present on the bone at all beyond the thickness of its cortex, then it would not be possible to determine the orientation, part of the shaft, or even the skeletal element. As this study has shown, even when these three aspects are known and are compared directly, differences between human and non-human bone thicknesses may not be clear. The means of the shaft diameters of the human skeletal elements have been included in these results because, in certain circumstances, the combination of the shaft diameter with the cortical bone thickness may assist with, if not positively identify, some shaft fragments. However, if the shaft diameter can be determined, then this in combination with the cortical bone thickness may be compared with the data presented here to assist with, if not always a positive identification, at least the elimination of some possibilities. For example, a fragment of adult human femur would have a thick cortex relative to its shaft that would eliminate some other non-human possibilities, even if no other information was available on the fragment. In commingled cases, where other more complete fragments indicate which species or even elements may be present, these osteometric features can be helpful in sorting fragments. Thus, these results mean that shaft diameter and cortical bone thickness can, in some cases, act as another morphological feature, to be added to a suite of features that may be used as clues during bone identification. Although workers may have used the general idea of fragment size before to help eliminate bones outside the human size range during identification, the presentation of these data here provides the valuable quantitative support that is welcomed by the legal system.

\section{Conclusions}

This study investigated the comparative cortical bone thickness in long bone shafts between humans and a range of common non-human mammals. Although both actual and relative cortical bone thickness were compared, it cannot be stated that either human or non-human bone as a whole is generally thicker. Rather, the particular non-human taxon, skeletal element or even part of the shaft 
under consideration affects whether the human variable is significantly greater, significantly less, or is no different than the corresponding non-human variable. In general, the clearest trend in absolute cortical bone thickness is that cattle bone cortices are thicker than those of humans; and for relative cortical bone thickness, the human femur is greater than the non-human femora tested here for all but the most distal parts of its shaft. The mean figures for many of the tested variables have been presented to introduce some much-needed objective criteria into this area of research. Very few studies have provided the actual dimensions of bone shafts and cortices, which can be more helpful than indices alone when looking at actual bone fragments. Although the use of cortical bone thickness measurements was found to be an inappropriate method to positively identify the majority of unknown bone fragments as human or non-human in origin, by presenting these data (especially the human samples), at least some fragments, such as those of large diameter bone shafts, may be objectively eliminated as human in origin. 


\section{References}

1 Saulsman, B., Oxnard, C.E. and Franklin, D. (2010) Long bone morphometrics for human from non-human discrimination. Forensic Science International 202:110.e1-110.e5.

2 Cattaneo, C., DiMartino, S., Scali, S., Craig, O.E., Grandi, M. and Sokol, R.J. (1999) Determining the human origin of fragments of burnt bone: a comparative study of histological, immunological and DNA techniques. Forensic Science International 102:181-191.

3 Crescimanno, A. and Stout, S.D. 2012 Differentiating fragmented human and nonhuman long bone using osteon circularity. Journal of Forensic Sciences 57(2):287-294.

4 Greenlee, D.M. and Dunnell, R.C. (2010) Identification of fragmentary bone from the Pacific. Journal of Archaeological Science 37:957-970.

5 Martiniaková, M., Grosskopf, B., Omelka, R., Vondráková, M. and Bauerová, M. (2006)

Differences among species in compact bone tissue microstructure of mammalian skeleton: use of a discriminant function analysis for species identification. Journal of Forensic Sciences 51(6):12351239.

6 Mulhern, D.M. and Ubelaker, D.H. (2001) Differences in osteon banding between human and nonhuman bone. Journal of Forensic Sciences 46(2):220-222.

7 Urbanová, P. and Novotný, V. (2005) Distinguishing between human and non-human bones: histometric method for forensic anthropology. Anthropologie 43:77-85.

8 Ubelaker, D.H., Lowenstein, J.M. and Hood, D.G. (2004) Use of a solid-phase double antibody radioimmunoassay to identify species from small skeletal fragments. Journal of Forensic Sciences 49(5):924-929.

9 Beckett, S., Rogers, K.D. and Clement, J.G. (2011) Inter-species variation in bone mineral behaviour upon heating. Journal of Forensic Sciences 56(3):571-579.

10 Matsuda, H., Seo, Y., Kakizaki, E., Kozawa, S., Muraoka, E. and Yukawa, N. (2005) Identification of DNA of human origin based on amplification of human-specific mitochondrial cytochrome $b$ region. Forensic Science International 152:109-114. 
11 Newman, M., Parboosingh, J.S., Bridge, P.J. and Ceri, H. (2002) Identification of archaeological animal bone by PCR/DNA analysis. Journal of Archaeological Science 29:77-84.

12 Parson, W., Pegoraro, K., Niederstätter, H., Föger, M. and Steinlechner, M. (2000) Species identification by means of the cytochrome b gene. International Journal of Legal Medicine 114:2328.

13 Brothwell, D.R. (1981) Digging up bones. $3^{\text {rd }}$ edn. British Museum (Natural History), London and Oxford University Press, Oxford, pp 36-43.

14 Ubelaker, D.H. (1989) Human skeletal remains: excavation, analysis, interpretation. $2^{\text {nd }}$ ed. Taraxacum, Washington, DC, pp 44-52.

15 Wolf, D.J. (1986) Forensic anthropology scene investigations. In: K.J. Reichs (ed.) Forensic osteology: advances in the identification of human remains. Charles C Thomas, Springfield, pp 3-24.

16 Croker, S.L., Clement, J.G. and Donlon, D. (2009) A comparison of cortical bone thickness in the femoral midshaft of humans and two non-human mammals. HOMO-Journal of Comparative Human Biology 60:551-565.

17 Foote, J.S. (1916) A contribution to the comparative histology of the femur. Smithsonian Contributions to Knowledge 35(3):1-242.

18 Urbanová, P. and Novotný, V. (2005) Distinguishing between human and non-human bones: histometric method for forensic anthropology. Anthropologie 43:77-85.

19 Rérolle, C., Saint-Martin, P., Dedouit, F., Rousseau, H. and Telmon, N. (2013) Is the corticomedullary index valid to distinguish human from nonhuman bones: a multislice computed tomography study. Forensic Science International 231:406.e1-406.e5.

20 Marshall, R. (2001) Living anatomy: structure as the mirror of function. Melbourne University Press, Melbourne, pp 91-133.

21 Bertelsen, P.K., Clement, J.G. and Thomas, C.D.L. (1995) A morphometric study of the cortex of the human femur from early childhood to advanced old age. Forensic Science International 74:63-77. 
22 Garn, S.M. (1970) The earlier gain and the later loss of cortical bone. Charles C Thomas, Springfield, IL, pp 45-50.

23 Feik, S.A., Thomas, C.D.L. and Clement, J.G. (1996) Age trends in remodelling of the femoral midshaft differ between the sexes. Journal of Orthopaedic Research 14:590-597.

24 Australian Government, Department of the Environment and Heritage (2005) Background information - 2006 Commercial kangaroo and wallaby harvest quotas online document viewed 21 October 2006, http://www.deh.gov.au/biodiversity/trade-use/publications/kangaroo/quotasbackground-2006.html

25 Australian Pork Ltd (2008) Australian Pig Annual 2006 - 2008. Australian Pork Ltd, Deakin West, ACT.

26 Australian Beef Association (2008) Market and trading options for beef producers: submission to ACCC Grocery Inquiry May 2008. Australian Beef Association, Oakey, QLD.

27 Addinsoft (2010) XLSTAT 2010, Data analysis and statistical software for Microsoft Excel. Paris, France.

28 Bushong, S.C. (2004) Radiologic science for technologists. $8^{\text {th }}$ edn. Elsevier Mosby, St Louis, MO, pp 283-285.

29 OsiriX Imaging Software, version 1.7.1.Pixmeo, Geneva.

30 Lund, P.J., Krupinski, E.A., Pereles, S. and Mockbee, B. (1997) Comparison of conventional and computed radiography: assessment of image quality and reader performance in skeletal extremity trauma. Academic Radiology 4(8):570-76.

31 Meema, H.E. and Meema, S. (1987) Postmenopausal osteoporosis: simple screening method for diagnosis before structural failure. Radiology 164:405-410.

32 Ives, R. and Brickley, M.B. (2004) A procedural guide to metacarpal radiogrammetry in archaeology. International Journal of Osteoarchaeology 14:7-17.

33 White, T.D. and Folkens, P.A. (2005) The human bone manual. Elsevier Academic Press, Amsterdam, pp 343. 
34 Kennedy, G.E. (1983) Some aspects of femoral morphology in Homo erectus. Journal of Human Evolution 12:587-616. 